University of Wollongong

Research Online

Faculty of Engineering and Information

Faculty of Engineering and Information

Sciences - Papers: Part A

Sciences

$1-1-2017$

High-strength steel plates in hybrid fiber-reinforced polymer-concrete-steel columns: concept and behavior

Tao Yu

University of Wollongong, taoy@uow.edu.au

Lip H. Teh

University of Wollongong, Iteh@uow.edu.au

Muhammad N. S Hadi

University of Wollongong, mhadi@uow.edu.au

Follow this and additional works at: https://ro.uow.edu.au/eispapers

Part of the Engineering Commons, and the Science and Technology Studies Commons

Research Online is the open access institutional repository for the University of Wollongong. For further information contact the UOW Library: research-pubs@uow.edu.au 


\title{
High-strength steel plates in hybrid fiber-reinforced polymer-concrete-steel columns: concept and behavior
}

\author{
Abstract \\ Applications of high-strength steel products in civil engineering have been limited by elastic local \\ buckling, by the perceived lack of ductility, and by the perceived difficulties of welding such steels. This \\ article proposes a new column (i.e. high-strength steel plate-concrete-filled fiber-reinforced polymer tube) \\ consisting of an outer fiber-reinforced polymer tube, concrete infill, and encased high-strength steel plates \\ that are connected to each other by bolted angle brackets at discrete elevations. The column offers an \\ ideal opportunity for the use of high-strength steel plates in construction, with their high yield stresses \\ being fully utilized and without welding (and without welding residual stresses). The rationale for the \\ column form and its expected advantages are explained and demonstrated through laboratory tests. \\ Prefabricated glass fiber-reinforced polymer tubes of 1.5 and $3.0 \mathrm{~mm}$ thick and $203 \mathrm{~mm}$ diameter were \\ infilled with concrete having a nominal strength of $32 \mathrm{MPa}$, with most specimens encasing steel plates of \\ various configurations and yield stresses ranging from 290 to $455 \mathrm{MPa}$. Results from concentric and \\ eccentric compression tests involving 13 specimens are presented to confirm the expected structural \\ advantages. The results demonstrated that the concrete in the tested specimens was very effectively \\ confined, and that buckling of all the steel plates was prevented by the encasing concrete up to and \\ beyond the rupture of the fiber-reinforced polymer tubes, leading to full structural utilization of the \\ construction materials and very ductile column responses under concentric and eccentric loadings. The \\ needs for future research on high-strength steel plate-concrete-filled fiber-reinforced polymer tube \\ columns are also discussed.

\section{Disciplines} \\ Engineering | Science and Technology Studies

\section{Publication Details} \\ Yu, T., Teh, L. H. \& Hadi, M. N. S. (2017). High-strength steel plates in hybrid fiber-reinforced \\ polymer-concrete-steel columns: concept and behavior. Advances in Structural Engineering: an \\ international journal, 20 (5), 797-811.
}




\title{
HIGH STRENGTH STEEL PLATES IN HYBRID FRP-CONCRETE-STEEL COLUMNS: CONCEPT AND \\ BEHAVIOUR
}

\author{
Tao Yu*, Lip H. Teh and Muhammad N.S. Hadi \\ School of Civil, Mining \& Environmental Engineering, \\ University of Wollongong, Wollongong, NSW 2522, Australia. \\ ${ }^{*}$ Corresponding author at School of Civil, Mining \& Environmental Engineering, University of \\ Wollongong, Wollongong, NSW 2522, Australia. Tel: +61242213786, E-mail: taoy@uow.edu.au
}

\begin{abstract}
Applications of high-strength steel products in civil engineering have been limited by elastic local buckling, by the perceived lack of ductility, and by the perceived difficulties of welding such steels. This paper proposes a new column (i.e. High Strength Steel Plate-Concrete Filled FRP Tube or HSSP-CFFT) consisting of an outer FRP tube, concrete in-fill and encased high-strength steel plates that are connected to each other by bolted angle brackets at discrete elevations. The column offers an ideal opportunity for the use of HSS plates in construction, with their high yield stresses being fully utilized and without welding (and without welding residual stresses). The
\end{abstract}


rationale for the column form and its expected advantages are explained and demonstrated through laboratory tests. Prefabricated glass FRP (GFRP) tubes of $1.5 \mathrm{~mm}$ and $3.0 \mathrm{~mm}$ thick and $203 \mathrm{~mm}$ diameter were in-filled with concrete having a nominal strength of $32 \mathrm{MPa}$, with most specimens encasing steel plates of various configurations and yield stresses ranging from 290 to $455 \mathrm{MPa}$. Results from concentric and eccentric compression tests involving 13 specimens are presented to confirm the expected structural advantages. The results demonstrated that the concrete in the tested specimens was very effectively confined, and that buckling of all the steel plates was prevented by the encasing concrete up to and beyond the rupture of the FRP tubes, leading to full structural utilization of the construction materials and very ductile column responses under concentric and eccentric loadings. The needs for future research on HSSP-CFFT columns are also discussed.

\section{INTRODUCTION}

The use of high-strength materials is often preferred when reductions in structural self-weight and/or size are important. A significant number of studies (e.g. Rasmussen and Hancock 1995; Zhao et al. 2004; Ban et al. 2013) have thus been conducted on high-strength steel (HSS) products, but their applications in civil engineering structures are rather limited at present. HSS typically refers to steel with a yield stress not lower 
than $450 \mathrm{MPa}$ (Li et al. 2013). The common HSS grades available nowadays, denoted differently in different countries (e.g. Q690 in China versus S690 in Europe), have yield stresses of $460 \mathrm{MPa}, 690 \mathrm{MPa}$ and $960 \mathrm{MPa}$, and steel with a yield stress greater than $690 \mathrm{MPa}$ may also be referred to as ultra-high-strength steel (Li et al. 2013). A major limiting factor for HSS is that its high yield stress cannot be fully utilized due to buckling under compression (e.g. in columns). Efforts to prevent local buckling of structural columns include filling a steel tube with concrete (i.e. concrete-filled tube or CFT) or encasing a steel section (e.g. I-section) in concrete (Uy 2001; Pocock 2006). However, these techniques have had limited success for HSS sections: in the former columns, local outward buckling of the steel tube still occurs; in the latter columns, the concrete typically crushes under compression at an axial strain between $0.2 \%$ to $0.3 \%$, which may be much lower than the yield strain of HSS (e.g. a yield stress of $690 \mathrm{MPa}$ leads to a yield strain of around $0.35 \%$ ). As a result, in both forms of columns, the HSS component can still buckle well before the yield strain is reached. Even when buckling occurs close to the yield strain, the subsequent response of the column is non-ductile, which is highly undesirable for structures designed for seismic resistance. Furthermore, fabricated steel sections require welding of the plate components, which adds to the fabrication cost especially for high strength steel. The presence of welding residual stresses also reduces the load-carrying capacity of the plates, and complicates the structural design procedure unless simplifying conservative assumptions are made. 
On the other hand, the hybrid use of Fiber Reinforced Polymer (FRP) and traditional materials (i.e. steel and concrete) to form new high-performance structures has attracted increasing research attention (e.g. Fam and Rizkalla 2001; Teng et al. 2007a; Yu and Teng 2011; Karimi et al. 2011; Zhang et al. 2015). In particular, filament-wound FRP tubes with fibres oriented close to the hoop direction are attractive for use with steel and concrete to form hybrid columns. These FRP tubes act as an external skin to protect the column from steel corrosion, as a confining device to enhance the strength and ductility of the concrete, and as a stay-in-place form to cast the concrete. A number of hybrid FRP-concrete-steel columns based on FRP confining tubes have thus emerged in recent years, including concrete-filled FRP tubes with or without an inserted steel section (Yu and Teng 2011; Karimi et al. 2011), and FRP-concrete-steel double-skin tubular members consisting of an outer FRP tube, an inner steel tube and a concrete infill in between (Teng et al. 2007a; Zhang et al. 2015). Existing studies generally revealed that these columns possess excellent structural performance, particularly ample ductility.

Against the above background, the authors recently proposed a novel solution to the problem of local buckling by fully encasing high strength steel plates in concrete that is cast in an FRP confining tube. The resulting structural member, referred to hereafter as concrete-filled FRP tube with HSS plates (or HSSP-CFFT), consists of an outer FRP 
tube, a concrete in-fill and a number of encased high-strength steel plates (Figure 1). In the novel column, the FRP tube offers mechanical resistances primarily in the hoop direction to confine the concrete and to enhance the shear resistance of the column, while the steel plates act as the main longitudinal reinforcement. One novel aspect of the column is that no welding is involved to fabricate the high strength steel sections, reducing the fabrication and transportation costs. Importantly, it obviates the perceived difficulties with welding high strength steels among the structural engineering profession. The individual steel plates can be connected to each other by angle brackets at discrete locations to facilitate their placement inside the FRP tube prior to casting concrete. By doing so, the angle brackets also serve as (1) shear connectors between the steel plates and concrete for improved composite action; and (2) restraints to the individual plates leading to reduced buckling lengths. The other novel aspect of the column is that it allows the configurations of the steel plates to be optimized for particular applications, which may not be in the shape of traditional sections such as I-section. The novel column may be constructed in-situ or precast, with the FRP tube acting as the stay-in-place form. The section form shown in Figure 1 consists of a circular outer tube and four steel plates, but many different combinations are possible (e.g. the outer tube can be square or rectangular, while more steel plates can be used to form a polygonal shape). 
The main advantages of HSSP-CFFTs include: (1) excellent ductility, as the concrete is well confined by the FRP tube and local buckling of the steel plates are constrained by the concrete; (2) excellent corrosion resistance, as the FRP tube is highly resistant to corrosion while the steel plates are protected by the FRP tube and the concrete; and (3) ease for construction, as the FRP tube act as a permanent form for casting concrete, and the welding of high-strength steel plates is avoided in the column. In addition, the full exploitation of the high yield stress of HSSP leads to significantly lighter columns that are cheaper to construct, as well as increased floor space in building construction.

As a first step in developing the new concept into a practical construction technology that can be routinely designed by structural engineers, a series of compression tests on HSSP-CFFTs were conducted. In parallel, tests were conducted on corresponding CFFTs without steel plates for comparison. This paper presents results from the compression tests which demonstrate some of the expected advantages of the new hybrid columns.

\section{EXPERIMENTAL PROGRAM}

\subsection{Test Specimens}


A total of 13 specimens were constructed and tested, comprising 11 HSSP-CFFT specimens and 2 CFFT specimens without steel plates. Three HSSP-CFFT specimens were tested under eccentric compression, while the rest were tested under concentric compression. All specimens had a nominal diameter of $203 \mathrm{~mm}$ (i.e. inner diameter of the FRP tube), and a height of $600 \mathrm{~mm}$ (for those under concentric compression) or 800 mm (for those under eccentric compression). For the HSSP-CFFT specimens, two configurations of steel plates were adopted, one with a single plate placed along a centre line of the cross-section while the other consisting of four plates connected together by bolted angle brackets to form a square (referred to as "square plate configuration" hereafter). The bolted angle brackets were used only near the ends of the specimens, and thus had little effect on their behavior. The widths of the steel plates were so designed that the concrete cover had a minimum thickness of around $20 \mathrm{~mm}$. As a result, the steel plates used in the single-plate specimens had a width of $160 \mathrm{~mm}$ (Figure 2a), while those used in the square-plate specimens had a width of $85 \mathrm{~mm}$ or $95 \mathrm{~mm}$, depending on the thickness of the plates (Figure $2 \mathrm{~b}$ and $2 \mathrm{c}$ ). The steel plates had a nominal yield stress of $450 \mathrm{MPa}$ or $290 \mathrm{MPa}$. Although the steel plates with a yield stress of $290 \mathrm{MPa}$ were not HSS plates, they were used in the present study for comparison, and all the specimens are referred to herein as HSSP-CFFT specimens for simplicity. The other main test variables included the thickness of the steel plates $(5 \mathrm{~mm}$ or $10 \mathrm{~mm}$ for 450 $\mathrm{MPa}$ HSSP) and that of the FRP tube $(1.5 \mathrm{~mm}$ or $3 \mathrm{~mm})$. The details of all the 
specimens are summarized in Table 1.

For ease of reference, each specimen is given a name (see Table 1), which starts with a letter "S" to represent "specimen", followed by a number $(0,1$ or 4$)$ to represent the number of steel plates in the specimen; this is then followed by a letter (from " $\mathrm{A}$ " to "C") to represent the type of steel plates (for HSSP-CFFT specimens only). The second number in the specimen name defines the thickness of the FRP tube, while the last letter "C" or "E" indicates that the specimen was tested under concentric or eccentric compression.

\subsection{Material Properties}

Two types of prefabricated glass FRP (GFRP) tubes were used in the present study. These GFRP tubes were all formed by a filament-winding process with a nominal fiber volume fraction of $59 \%$ and fiber winding angles of \pm 75 degrees to the longitudinal axis of the tube. The only difference between the two types of GFRP tubes was in their nominal thicknesses, which were $1.5 \mathrm{~mm}$ and $3 \mathrm{~mm}$, respectively. According to the manufacturer data, the tubes had elastic modulii equal to $33 \mathrm{GPa}$ in the hoop direction and $12 \mathrm{GPa}$ in the longitudinal direction. 
The 13 HSSP-CFFT and CFFT specimens were divided into two testing groups (see Table 1) and were tested at two different times. The specimens of Group 1 were tested after 32-34 days of curing while the other were tested two weeks later. As a result, the compressive strengths of the concretes in the two testing groups were slightly different. Plain concrete cylinders of two dimensions, namely, $150 \mathrm{~mm}$ x $300 \mathrm{~mm}$ and $100 \mathrm{~mm}$ x $200 \mathrm{~mm}$, were tested to determine the compressive strength of concrete. The $150 \mathrm{~mm}$ cylinder tests showed that the concrete in Group 1 had a compressive strength of 33.1 $\mathrm{MPa}$ while that in Group 2 had a compressive strength of $35.9 \mathrm{MPa}$. The compressive strengths obtained from the $100 \mathrm{~mm}$ cylinder tests were $44.7 \mathrm{MPa}$ and $48.0 \mathrm{MPa}$ for Groups 1 and 2, respectively.

Tensile tests on three steel coupons were conducted for each type of steel plates. The measured yield stresses of plates A, B and C were found to be $290 \mathrm{MPa}, 450 \mathrm{MPa}$ and $455 \mathrm{MPa}$, respectively.

\subsection{Preparation of Specimens}

The preparation process of the HSSP-CFFT specimens included the following steps: (1) preparation of steel plates, which involved cutting of the steel plates to the desired dimensions, attaching strain gauges on the steel plates and bolting the steel plates to 
form the square plate configurations; (2) fabrication of the mould, which consisted of an outer FRP tube with a centered steel plate configuration fixed to a wooden frame with a waterproof base plate (Figure 3); (3) casting the concrete; (4) strengthening of local regions which included the two regions each of a $75 \mathrm{~mm}$ height near the column ends and the regions near the holes drilled through the FRP tubes for passing the electric wires of the strain gauges on the steel plates. A similar preparation process was adopted for the CFFT specimens except that step (1) was not needed and steps (2) and (4) were simpler because of the absence of steel plates.

\subsection{Test Set-Up and Instrumentation}

For each specimen, four strain gauges with a gauge length of $20 \mathrm{~mm}$ or $30 \mathrm{~mm}$ were installed at the mid-height of the FRP tube to measure the hoop strains. These strain gauges were evenly distributed around the circumference of the FRP tube. For the specimens under eccentric compression, two additional axial strain gauges with a gauge length of $20 \mathrm{~mm}$ or $30 \mathrm{~mm}$ were attached at the mid-height of the FRP tube. For each steel plate in the HSSP-CFFT specimens, two axial strain gauges with a gauge length of $10 \mathrm{~mm}$ were attached on the two faces respectively at the mid-height. In addition, two linear variable displacement transducers (LVDTs) were used to measure the total axial shortening of each specimen, and a laser displacement transducer was used to measure 
the lateral deformation of the compression side at the mid-height of each eccentrically-loaded specimen.

For the three specimens under eccentric compression, a custom designed steel cap with arc-shaped grooves was used in conjunction with a steel plate with a V-block so that the desired load eccentricity could be accurately obtained (Figure 4a and 4b). The load eccentricity was $25 \mathrm{~mm}$ for the all the three specimens, and was with respect to a center line perpendicular to the single steel plate for specimen S1B-3-E (Figure 4c).

All compression tests were carried out using a 500 ton Denison compression testing machine with a displacement control rate of $0.5 \mathrm{~mm} / \mathrm{min}$. The FRP tube and the concrete were loaded simultaneously during the test (Figure 4a). All test data, including the strains, loads, and displacements, were recorded simultaneously by a data logger.

\section{RESULTS OF CONCENTRIC COMPRESSION TESTS}

\subsection{General Behavior}

All the specimens under concentric compression displayed continuous load-shortening behavior with a monotonically increasing load until the ultimate failure due to rupture 
of the FRP tube under hoop tension, except specimen S4C-3-C for which the test was terminated when the load approached the capacity of the testing machine. The rupture of FRP tube generally initiated from a hole, although that region was locally strengthened. The holes were drilled for passing the electric wires of strain gauges, and were located at around one quarter of the column height. This means that the hoop rupture strain of FRP recorded in these tests may be well below that could be reached in a real column with an intact FRP tube, but the effect of the small holes on the overall behavior of the column before the ultimate failure is believed to be minor.

\subsection{Axial Load-Shortening Behavior}

The key test results of all the ten specimens under concentric compression are summarized in Table 2. In this table, $P_{c}$ is the ultimate load obtained in the test, $P_{s}$ is equal to the squash load of the steel plates, and $P_{c o}$ is equal to the unconfined concrete strength times the net cross-section area of concrete.

Typical axial load-shortening curves of the specimens with a $1.5 \mathrm{~mm}$ FRP tube are shown in Figure 5, where the axial shortenings were averaged from the two LVDT readings. In this paper, the experimental curves in figures are terminated at the point when FRP rupture occurred, unless otherwise specified. It is evident that all the 
specimens had a bilinear axial load-shortening curve with two ascending branches. Because steel has a larger elastic modulus than concrete, the two HSSP-CFFT specimens had a larger initial stiffness than their CFFT counterparts (Figure 5).

The second linear branches of the curves of the three specimens, however, were approximately parallel to each other (i.e. had a similar slope) (Figure 5). Further examination of the curves reveals that for all the three specimens in Figure 5, the transition point between the two branches of the curve happened at a load which was approximately equal to $P_{c o}+P_{s}$ of the specimen. Considering the fact that the steel plates had yielded at the beginning of the second branch, as also evidenced by the readings of strain gauges attached on the steel plates, it can be deduced that the load increase in the second branch came mainly from the confinement effect of the FRP tube to the concrete, except that some load increase near the end of test may have been caused by the strain hardening of the steel plates. This also explains the approximately parallel second linear branches of the three curves in Figure 5, where the differences in the load of the three linear branches at an arbitrary shortening are approximately equal to the differences in the $P_{c o}+P_{s}$ values.

It is also obvious that the HSSP-CFFTs reached ultimate loads that are significantly (up to $129 \%$ ) higher than the simple sum of the squash loads of the steel plates and the 
unconfined strength of the concrete (Table 2). It may be noted that the FRP tubes did not contribute directly to the ultimate loads.

\subsection{Buckling of Steel Plates}

In HSSP-CFFT specimens, the steel plates were restrained by the encasing concrete and the FRP tube. As a result, their propensity to buckle was reduced. The steel plates of all tested HSSP-CFFT specimens were taken out for examination. Figure 6 shows the plates taken out from the specimens with a single plate while Figure 7 shows those taken out from the specimens with a square plate configuration. It is evident from Figure 6 that the plates remained straight after test without any visible buckling deformation. However, for the plates which formed a square configuration, Figure 7 shows that most of them, especially those in specimens with a thin FRP tube, experienced significant buckling deformation. The only exception was the square plate configuration taken out from specimen S4C-3-C (Figure 7c). To further examine this issue, readings from the four pairs of strain gauges attached on the four steel plates in specimen S4A-3-C are shown in Figure 8 (the strain gauge readings from other specimens with a square plate configuration were similar). In the legend of Figure 8, "S1" to "S4" represent the four steel plates, respectively, and the last number "1" or "2" is used to differentiate reading from two strain gauges attached on the same steel plate. 
In this paper, a tensile strain is positive and a compressive strain is negative unless otherwise specified. Figure 8 shows that the four pairs of strain gauges recorded very similar strains at the beginning of test until a strain value which was approximately equal to the yield strain of the steel; after that the strain readings appeared somewhat erratic, which might be due to uneven yielding of the steel plates. Nevertheless, after a short period, all the eight strain gauges started to increase monotonically again at similar rates until the rupture of FRP tubes. There was no evidence that the two strain gauges of any pair (i.e. the two strain gauges attached on the two faces of a plate) displayed noticeable strain gradient over the thickness of a steel plate, suggesting that buckling deformation near the mid-height region was unlikely to occur before the rupture of the FRP tube. The fact that the strains of all the plates kept increasing (i.e. no unloading) suggests that buckling away from the mid-height region was also unlikely to occur before the FRP rupture. Considering also the fact that the four steel plates in specimen S4C-3-C, whose test was terminated before the FRP rupture, did not show any visible buckling deformation, it may be reasonable to conclude that the buckling of steel plates shown in Figures $7 \mathrm{a}$ and $\mathrm{b}$ for specimens with a square plate configuration occurred only after the rupture of FRP tube, when the plates lost their buckling restraint. This conclusion is also supported by the axial load-shortening curves shown in Figure 5, which suggests that the contribution of steel plates did not decrease before the FRP tubes ruptured. 


\subsection{Effect of Steel Grade}

For the steel plates in the HSSP-CFFT specimens, their yield stresses were fully exploited as no buckling occurred before the respective FRP tubes ruptured, by which time the compressive strains were multiple times the respective yield strains. Therefore, the effect of steel grade is clearly reflected in the axial load-shortening curves shown in Figure 5 in terms of the intersection of the second linear branch and the load axis, which increased with the yield stress of the steel plates.

Figure 9 compares two groups of specimens with a $3 \mathrm{~mm}$ FRP tube and the same observations can generally be made. In Figure 9a, the initial stiffness of specimen S4C-3-C is seen to be higher than that of the other two HSSP-CFFT specimens, which was due to the significantly larger thickness and thus larger cross-section area of its steel plates. In Figure 9b, the curve of specimen S1B-3-C is not higher than that of S1A-3-C as may be expected. This may be due to the relatively small difference in the contributions of the steel plates between the two specimens as a proportion of their ultimate loads, and to the variability of the concrete strength. Given that both plates A and $\mathrm{B}$ had a thickness of around $5 \mathrm{~mm}$, it was also possible that a wrong plate (i.e. plate A instead of plate B) was used in specimen S1B-3-C. 


\subsection{Effect of Thickness of FRP Tube}

It has been well established that the behavior of FRP-confined concrete specimens depends on the amount of confining FRP. When all other parameters are the same, a thicker FRP tube leads to greater increases in strength and ductility of the confined concrete. Figure 10 compares three pairs of CFFT or HSSP-CFFT specimens where the only difference between the two specimens in each pair was the thickness of FRP tube (i.e. $1.5 \mathrm{~mm}$ or $3 \mathrm{~mm}$ ). It is evident that, compared to those with a $1.5 \mathrm{~mm}$ FRP tube, the specimens with a $3 \mathrm{~mm}$ FRP tube invariably developed curves with a higher/stiffer second branch and achieved higher load capacity and larger ductility (see also Table 2).

\subsection{Effect of Configuration and Thickness of Steel Plates}

In the present study, the steel plates in all the specimens did not experience buckling before the respective FRP tubes ruptured, so the effects of the configuration and thickness of the steel plates came mainly from the initial stiffness and the squash load of the plates. Figure 11 compares three groups of specimens where the only difference among the three specimens in each group was the steel plate configuration. As expected, the following observations can generally be made from Figure 11 for the three curves in 
each group: (1) the slopes of the first branches were different due to the difference in the cross-section area of the steel plates; (2) the second branches were approximately parallel to each other where the differences represented approximately the differences in the squash load of steel plates.

However, it should be noted that in the specimens with a square plate configuration, buckling of steel plates happened soon after the respective FRP tubes ruptured (Figure 7), but the same phenomenon did not occur for the specimens with a single plate (Figure 6). This is believed to be due to the difference in the thickness of the concrete cover of the plates. It should also be noted that the thin FRP tubes (i.e. $1.5 \mathrm{~mm}$ tubes) used in the present study already had a large confinement stiffness which led to a strength increase of around $90 \%$ for the concrete. In practice, FRP tubes with a confinement stiffness smaller than these tubes may be used, and therefore buckling of the steel plates, which is affected by both the concrete cover thickness and the FRP tube stiffness, may be an issue needing further investigation.

\subsection{Lateral Dilation Behavior}

It is now well established that the lateral dilation behavior of confined concrete is the key parameter controlling the effectiveness of FRP confinement and has been 
investigated by many researchers (e.g. Teng et al. 2007b; Yu et al. 2010). The existence of additional steel plates that are not axis-symmetrically placed in HSSP-CFFT specimens means that the confinement received by the concrete is generally non-uniform. The lateral dilation behavior of the column is further complicated by possible buckling of the steel plates.

To examine the aforementioned issues, the axial strain-hoop strain curves of all the specimens are shown in Figure 12, where the hoop strains were averaged from the readings of four strain gauges installed on the FRP tubes (except that the average values of two strain gauge readings were used for specimen S4A-1-C as the other two strain gauges were damaged during the test). The axial strains shown in Figure 12 were obtained by dividing the axial shortenings by the height of the specimen. As a result, these axial strains represent the average deformation of the concrete over the column height, where the deformations near the ends are expected to be different from that near the mid-height because of the lateral restraints from the two end loading plates. The existence of such differences, as well as the likely deformation of the loading equipment, generally leads to larger axial strains especially in the initial stage of loading. Nevertheless, these strain values still provide a reasonable measure for the mid-height axial deformation of concrete especially for the later stage of loading, as also evidenced by a comparison with the readings of strain gauges attached at the mid-height of steel 
plates.

The curves in Figure 12 are grouped in three subfigures, each of which includes specimens with the same FRP tubes and different steel plates. It is evident from Figure 12 that the curves in each subfigure are generally well aligned with each other, suggesting that the existence of steel plates does not have a significant effect on the overall lateral dilation behavior of HSSP-CFFT columns. However, some differences did exist: the lateral dilation of HSSP-CFFT specimens was generally somewhat larger than their CFFT counterparts at the same axial strain, especially for specimens with a $1.5 \mathrm{~mm}$ FRP tube (Figure 12a). Future research is needed to further investigate this issue, especially for FRP tubes with a small circumferential stiffness.

As the failure of an HSSP-CFFT column is governed by the rupture of the FRP tube, the hoop rupture strain is an important factor controlling the ultimate load and ductility of the column. It determines the termination point of the axial strain-hoop strain curves (Figure 12), and thus the ultimate axial strain of the column. When all other parameters are the same, a larger FRP rupture strain leads to a longer second branch of the axial load-shortening curve, which terminates at a higher ultimate load and axial shortening. In the present study, the hoop rupture strain of FRP was significantly affected by the local imperfection (i.e. drilled holes) and thus did not represent the full capacity of the 
FRP tube. Future research is needed to avoid this imperfection in the preparation of specimens, and to develop a rational design method for the ultimate limit state of HSSP-CFFT columns.

\subsection{Comparison with Lam and Teng's (2003) Model}

Based on the results presented in Figure 12, it is reasonable to expect that the ultimate load of an HSSP-CFFT column can be predicted using: (1) an existing stress-strain model for FRP-confined concrete to calculate the contribution of concrete; and (2) the squash load of steel plates to determine the contribution of the steel plates. In the present study, Lam and Teng's (2003) model, which has been adopted by a number of design codes/guidelines (e.g. GB 50608 2011; ACI 440 2008), was adopted for calculating the strength of the confined concrete. The compressive strength of FRP-confined concrete $f_{c c}^{\prime}$ can be predicted by the following equations:

$$
\begin{gathered}
\frac{f_{c c}^{\prime}}{f_{c o}^{\prime}}=1+3.3 \frac{f_{l}}{f_{c o}^{\prime}} \text { when } f_{l} / f_{c o}^{\prime} \geq 0.07 \\
f_{l}=\frac{E_{f r p} t_{f r p} \varepsilon_{h, r u p}}{R}
\end{gathered}
$$

where $f_{c o}^{\prime}$ is the compressive strength of unconfined concrete found from the tests of standard cylinders with a diameter of around $150 \mathrm{~mm}, f_{l}$ is the maximum confining 
pressure provided by an FRP jacket, $E_{f r p}$ is the elastic modulus of FRP in the hoop direction, $t_{f r p}$ is the thickness of the FRP jacket, $\varepsilon_{h, \text { rup }}$ is the hoop rupture strain of FRP, $R$ is the radius of the confined concrete core.

The estimated ultimate loads are compared with the test results in Table 2. The following experimental parameters were used: (1) compressive strength of unconfined concrete found from the $150 \mathrm{~mm}$ cylinder tests; (2) hoop elastic modulus of FRP provided by the manufacturer; (3) hoop rupture strain of FRP obtained from the column tests; (4) yield stress of steel obtained from coupon tests. The direct contribution of the FRP tubes to the column's load capacity was ignored as the fibres were close to the hoop direction and the cross-section areas of the tubes were small.

Table 2 shows that the estimates obtained using Equations (1) and (2) were generally conservative, with the professional factors (i.e. the ratios of the peak test load to the estimated one) being around 1.18 for most specimens. The only exception was specimen S1B-3-C, for which the professional factor was 1.02. This may be due to the scatter in the concrete strength or the use of a wrong plate, as discussed above for the axial load-shortening curves (Figure 9b). The relatively low estimates for most specimens are believed to be mainly due to one or both of the following reasons: (1) the hoop elastic modulus of FRP provided by the manufacturer was conservative; and (2) the strain 
hardening of steel was not considered in the predictions. In addition, the steel plates may provide additional confinement to the concrete surrounded by them, but this effect was not considered in the model used in the present study.

\section{RESULTS OF ECCENTRIC COMPRESSION TESTS}

\subsection{General Observations}

All the specimens under eccentric compression displayed monotonic load-shortening behavior until ultimate failure by the hoop rupture of the FRP tube on the compression side (i.e. the side close to the load), except for specimen S4B-3-E, whose test was purposely terminated to examine the state of its steel plates post the peak load but before the FRP tube ruptured. During eccentric compression tests, the specimens were subjected to combined axial compression and flexure. As expected, the deformations of the specimens included axial shortening and bending (Figure 13). As the curvature and the lateral deflection increased, the actual load eccentricity/bending moment varied along the height and deviated from the initial value. The bending moment was the largest at the location of the largest lateral deflection which generally occurred at or close to the mid-height of the specimen. Besides the damage on the compression side, tensile cracks occurred on the tension side (i.e. the side away from the load) of the FRP 
tubes in the form of white patches along the fiber directions as a result of resin damage.

The steel plates of the three HSSP-CFFT specimens under eccentric compression were taken out after tests for further examination (Figure 14). It is evident that the steel plates in specimens S1B-3-E and S4A-3-E experienced significant bending but the deformation of those in specimen S4B-3-E was much smaller due to the early termination of the test post the peak load. Despite the large deformation of the plates, no local buckling was found on any of these plates, suggesting that the plates were well restrained in the HSSP-CFFT specimens.

\subsection{Axial Load-Shortening Behavior}

The axial load-shortening curves of the three specimens under eccentric compression are shown in Figure 15, where the curves of the corresponding specimens having the same nominal cross-sections and subjected to concentric compression are also plotted. As the concentrically-loaded specimens had a different height, the axial shortenings in Figure 15 are all normalized by the height of the specimens for ease of comparison. The axial shortenings were averaged from readings of the two LVDTs that were placed symmetrically with respect to the centre of the loading machine, so they represent the relative movement between the centers of the two loading plates of the machine (i.e. the 
two loading points). These axial shortenings were due to not only the axial deformation of the specimen but also the bowing deformation caused by bending. As a result, the specimens tested under eccentric loading were shown to have lower initial stiffnesses than their concentrically-loaded counterparts. The eccentrically-loaded specimens also had smaller axial load capacities due to the existence of bending moment. These specimens, however, all possessed excellent ductility, and their ultimate axial shortening could be even comparable to the corresponding specimens under concentric compression

\subsection{Longitudinal Strain Distribution over the Cross-section}

The cross-sectional distributions of longitudinal strains in the three specimens are illustrated in Figure 16, in which the horizontal axis represents the distance to the centerline of the specimen (Figure 4c) and the vertical axis represents the axial strain value. The longitudinal strains were measured by the strain gauges attached to the FRP tubes and the steel plates. For each specimen, several curves representing the strain distributions under different load levels are shown. For instance, the curves denoted as "500 kN" in Figure 16 represent the strain distributions at a load level of $500 \mathrm{kN}$. The following observations can be made from Figure 16: (1) The distributions of longitudinal strains generally remained approximately linear across the section (in the 
plane of bending) during the initial stage of loading; (2) As the load increased, tensile cracks occurred on the side farthest from the loading point; as a result the strain gauges spanning over the cracks recorded large tensile strains that deviated from the linear curve (see Figure 16b for an example) while those not crossed by but close to cracks recorded low tensile strains as the tensile strains were relaxed by the nearby cracks (e.g. in specimen S4A-3-E, see Figure 16c); (3) when the readings of the strain gauges on the steel plates exceeded their yield strain, some of them deviated significantly from the linear strain distribution (Figure 16c), which may be due to non-uniform plastic local deformation along the steel plates.

\subsection{Lateral Dilation Behavior}

Figure 17 shows the axial shortening-hoop strain curves for specimen S1B-3-E (the curves for the other two eccentrically-loaded specimens are similar). In Figure 17, a group of four curves are plotted, of which the hoop strains were measured by four strain gauges attached on the FRP tube respectively: H2 represents readings of the strain gauge on the tension side, $\mathrm{H} 4$ represents readings of the strain gauge on the compression side while $\mathrm{H} 1$ and $\mathrm{H} 3$ represent readings of two strain gauges along the centre line of the specimen. It is evident from Figure 17 that the hoop strain distribution over the cross-section was quite non-uniform, with the largest hoop strains occurring on 
the compression side where the FRP rupture happened. This means that the confining pressure received by the concrete in the column was also non-uniform, which may make the confinement by FRP tube less efficient than in concentrically loaded columns. The fact that the lateral dilation of concrete was non-uniform also means that the concrete in the compressive region may expand towards the tensile region, so the overall lateral

dilation behavior is much more complex and may not be comparable to that of concentrically loaded columns. It is also worth noting that the lateral dilation behavior may have been further complicated by the significant bending deformation of the steel plates.

\section{CONCLUSIONS}

This paper has presented the details of a newly proposed hybrid FRP-concrete-steel tubular column. The new column consists of an outer FRP tube, a concrete in-fill and a number of encased high-strength steel plates that are connected to each other by bolted angle brackets at discrete elevations. The new column, termed HSSP-CFFT (High Strength Steel Plate-Concrete Filled FRP Tube) in this paper, offers an ideal opportunity for the use of high-strength steel plates in construction, with the high yield stress of these plates being fully utilized and the perceived difficulties of welding high strength steels being obviated. No allowance needs be made for welding residual stresses, 
leading to simpler structural design procedures. The HSSP-CFFT column thus has many advantages compared to existing designs including its excellent corrosion resistance and ample ductility.

This paper has also presented results from concentric and eccentric compression tests to confirm the expected structural advantages. The results demonstrated that the concrete in the tested specimens was very effectively confined, and that buckling of the steel plates with yield stresses up to $455 \mathrm{MPa}$ was prevented by the encasing concrete up to and beyond the rupture of the FRP tubes, leading to full structural utilization of the construction materials and very ductile column responses.

For a concentrically loaded column, the imminence of steel plate buckling following rupture of the FRP tube may depend on the thickness of the concrete cover. This aspect requires further detail investigation. Another aspect worth investigating is the increase in the lateral dilation of an HSSP-CFFT column under compression in the presence of the steel plates, which is more pronounced with thin FRP tubes. In any case, the axial load capacity can be reasonably determined using well-established formulae.

In an HSSP-CFFT column subjected to combined compression and bending, the steel plates may undergo very substantial deformations without local buckling. However, the 
lateral dilation behaviour of such a column is more complex compared to one subjected to uniform compression only, and its load capacity may not be directly determined using existing formulae.

\section{ACKNOWLEDGEMENTS}

The authors are grateful for the financial supports received from the University of Wollongong and Bluescope Ltd through a URC Research Partnerships project as well as the Australian Research Council through a Discovery Early Career Researcher Award (Project ID: DE140101349) for the first author. The authors also wish to thank Prof. Jin-Guang Teng of The Hong Kong Polytechnic University for his valuable suggestions during the conceptual development of the new column form, and Messrs Jalen Price and Andrew Meharg for their valuable contribution to the experimental work.

\section{REFERENCES}

ACI 440 (2008). Guide for the Design and Construction of Externally Bonded FRP Systems for Strengthening Concrete Structures, American Concrete Institute, Farmington Hills, MI, USA. 
Ban, H.Y., Shi, G., Shi, Y.J. and Bradford, M.A. (2013). "Experimental investigation of the overall buckling behaviour of $960 \mathrm{MPa}$ high strength steel columns," Journal of Constructional Steel Research, 88, 256-266.

Fam, A.Z. and Rizkalla, S.H. (2001). "Behavior of axially loaded concrete-filled circular fiber-reinforced polymer tubes", ACI Structural Journal, 98(3), pp. 280-289.

GB 50608 (2011). Technical Code for Infrastructure Application of FRP Composite, China Planning Press, Beijing, China. (in Chinese)

Karimi, K., Tait, M.J. and El-Dakhakhni, W.W. (2011). "Test and modelling of a novel FRP-encased steel-concrete composite columns", Composite Structures, Vol. 93, pp. 1463-1473.

Lam, L. and Teng, J.G. (2003). "Design-oriented stress-strain model for FRP-confined concrete", Construction and Building Materials, 17, pp. 471-489.

Li, G.Q., Wang, Y.B., Chen, S.W. and Sun, F.F. (2013). "State-of-the-art on research of high strength structural steels and key issues of using high strength steel in seismic structures”, Journal of Building Structures, 34(1), 1-13 (in Chinese).

Pocock, G. (2006). "High strength steel use in Australia, Japan and the US", The Structural Engineer, 84, 27-30. 
Rasmussen, K., and Hancock, G. (1995). "Tests of high strength steel columns," Journal of Constructional Steel Research, 34, 27-52.

Teng, J.G., Yu, T., Wong, Y.L. and Dong, S.L. (2007a). "Hybrid FRP-concrete-steel tubular columns: concept and behavior", Construction and Building Materials, 21(4), pp. 846-854.

Teng, J.G., Huang, Y.L., Lam, L. and Ye, L.P. (2007b). "Theoretical model for fiber-reinforced polymer-confined concrete", Journal of Composites for Construction, ASCE, 11(2), 201-210.

Uy, B. (2001). "Strength of short concrete filled high strength steel box columns", Journal of Constructional Steel Research, 57, 113-134.

Yu, T., Teng, J. G. and Wong, Y. L. (2010). "Stress-strain behavior of concrete in hybrid FRP-concrete-steel double-skin tubular columns", Journal of Structural Engineering, ASCE, 136(4), 379-389.

Yu, T. and Teng, J.G. (2011). "Design of concrete-filled FRP tubular columns: Provisions in the Chinese Technical Code for Infrastructure Application of FRP Composites”, Journal of Composites for Construction, ASCE, 15(3), pp. 451-461.

Zhang, B., Yu, T. and Teng, J.G. (2015). "Behaviour of concrete-filled FRP tubes under cyclic-axial compression”, Journal of Composites for Construction, 19(3), 04014060 . 
Zhao, X.L., Van Binh, D., Al-Mahaidi, R. and Tao, Z. (2004). "Stub column tests of fabricated square and triangular sections utilizing very high strength steel tubes", Journal of Constructional Steel Research, 60, 1637-1661. 
Table 1. Specimen details

\begin{tabular}{|c|c|c|c|c|c|c|c|}
\hline \multirow{2}{*}{ Specimen } & \multirow{2}{*}{$\begin{array}{l}\text { Configuration } \\
\text { of steel plates }\end{array}$} & \multicolumn{3}{|c|}{ Steel Plates } & \multirow{2}{*}{$\begin{array}{l}\text { Thickness of } \\
\text { FRP tubes } \\
(\mathrm{mm})\end{array}$} & \multirow{2}{*}{$\begin{array}{l}\text { Loading } \\
\text { scheme }\end{array}$} & \multirow{2}{*}{$\begin{array}{l}\text { Testing } \\
\text { group }\end{array}$} \\
\hline & & Type & $\begin{array}{l}\text { stress } \\
(\mathrm{MPa})\end{array}$ & $\begin{array}{l}\text { Thickness } \\
\text { (mm) }\end{array}$ & & & \\
\hline S0-3-C & \multirow{2}{*}{\multicolumn{4}{|c|}{ N/A }} & 3 & Concentric & 1 \\
\hline S0-1-C & & & & & 1.5 & Concentric & 1 \\
\hline S1A-3-C & Single & \multirow{4}{*}{ A } & \multirow{4}{*}{290} & \multirow{4}{*}{4.95} & 3 & Concentric & 1 \\
\hline S4A-3-C & Square & & & & 3 & Concentric & 1 \\
\hline S4A-1-C & Square & & & & 1.5 & Concentric & 2 \\
\hline S4A-3-E & Square & & & & 3 & Eccentric & 2 \\
\hline S1B-3-C & Single & \multirow{5}{*}{ B } & \multirow{5}{*}{450} & \multirow{5}{*}{5.00} & 3 & Concentric & 1 \\
\hline S4B-3-C & Square & & & & 3 & Concentric & 1 \\
\hline S4B-1-C & Square & & & & 1.5 & Concentric & 2 \\
\hline S1B-3-E & Single & & & & 3 & Eccentric & 2 \\
\hline S4B-3-E & Square & & & & 3 & Eccentric & 2 \\
\hline S1C-3-C & Single & \multirow{2}{*}{$\mathrm{C}$} & \multirow{2}{*}{455} & \multirow{2}{*}{10.0} & 3 & Concentric & 1 \\
\hline S4C-3-C & Square & & & & 3 & Concentric & 1 \\
\hline
\end{tabular}


Table 2. Key test results of specimens under concentric compression

\begin{tabular}{|c|c|c|c|c|c|c|c|}
\hline Specimen & $\begin{array}{l}\text { Ultimate } \\
\text { load } P_{c} \\
(\mathrm{kN})\end{array}$ & $\begin{array}{c}\text { Squash load } \\
\text { of steel } \\
\text { plates } P_{s} \\
(\mathrm{kN})\end{array}$ & $\begin{array}{c}\text { Unconfined } \\
\text { strength of } \\
\text { concrete section } \\
P_{c o}(\mathrm{kN}) \\
\end{array}$ & $\frac{P_{c}}{\left(P_{c o}+P_{s}\right)}$ & $\varepsilon_{h, \text { rup }}$ & $\begin{array}{l}\text { Predicted } \\
\text { Ultimate } \\
\text { Load } P_{c, p} \\
\quad(\mathrm{kN})\end{array}$ & $\frac{P_{c}}{P_{c, p}}$ \\
\hline S0-3-C & 3394.0 & \multirow{2}{*}{0} & \multirow{2}{*}{1165.2} & 2.91 & 0.0176 & 2904.8 & 1.17 \\
\hline S0-1-C & 2250.2 & & & 1.93 & 0.0164 & 1925.5 & 1.17 \\
\hline S1A-3-C & 2981.8 & 229.7 & 1136.6 & 2.18 & 0.0120 & 2494.3 & 1.20 \\
\hline S4A-3-C & 3774.3 & 545.5 & 1097.4 & 2.29 & 0.0167 & 3193.2 & 1.18 \\
\hline S4A-1-C & 3140.8 & 545.5 & 1097.4 & 1.91 & 0.0233 & 2783.0 & 1.13 \\
\hline S1B-3-C & 3030.8 & 360 & 1136.4 & 2.02 & 0.0153 & 2959.3 & 1.02 \\
\hline S4B-3-C & 4191.1 & 855 & 1096.8 & 2.15 & 0.0170 & 3530.4 & 1.19 \\
\hline S4B-1-C & 3486.5 & 855 & 1096.8 & 1.79 & 0.0202 & 2939.1 & 1.19 \\
\hline S1C-3-C & 3700.1 & 720 & 1107.6 & 2.02 & 0.0135 & 3075.2 & 1.20 \\
\hline S4C-3-C & 4646.1 & 1530 & 1042.8 & 1.81 & 0.0158 & 3961.8 & 1.17 \\
\hline
\end{tabular}

Table 3. Key test results of specimens under eccentric compression

\begin{tabular}{|c|c|c|c|}
\hline Specimen & $\begin{array}{c}\text { Ultimate } \\
\text { load } P_{c} \\
(\mathrm{kN})\end{array}$ & $\begin{array}{c}\text { Ultimate } \\
\text { axial } \\
\text { shortening } \\
(\mathrm{mm})\end{array}$ & $\varepsilon_{\text {h,rup }}$ \\
\hline S4A-3-E & 1527.3 & 17.9 & 0.0072 \\
\hline S1B-3-E & 1516.3 & 19.6 & 0.0092 \\
\hline S4B-3-E & 1831.1 & $/$ & $/$ \\
\hline
\end{tabular}





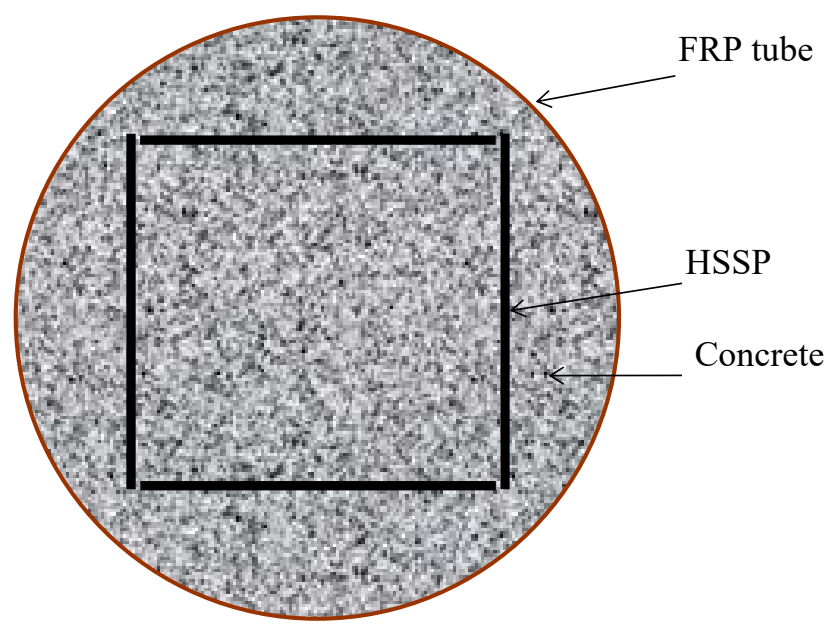

Figure 1. Typical cross-section of HSSP-CFFT

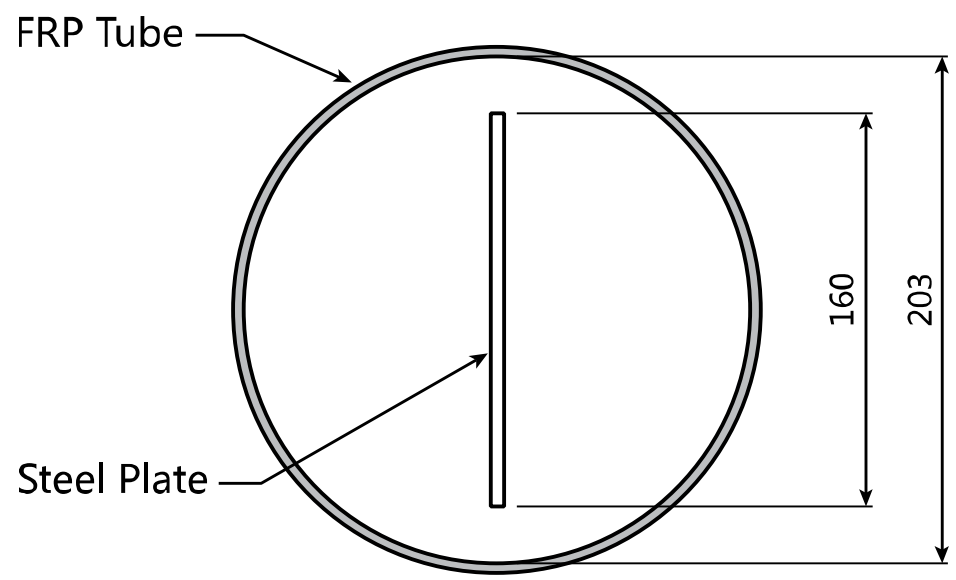

(a) Cross-section of HSSP-CFFTs with plate A 


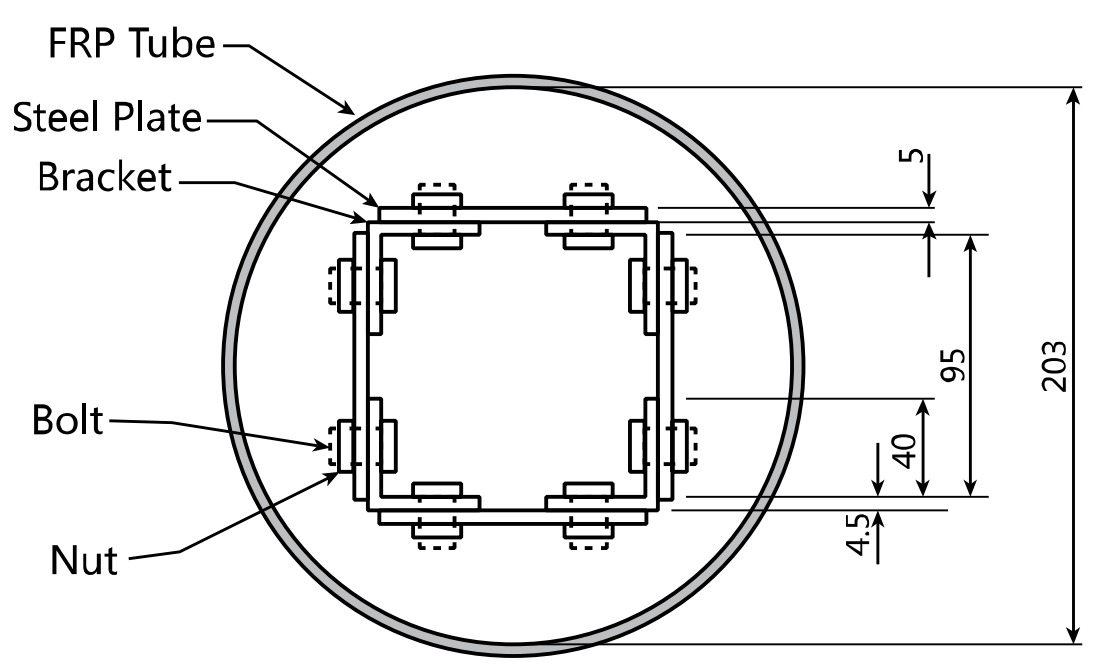

(b) Cross-section of HSSP-CFFTs with plate B

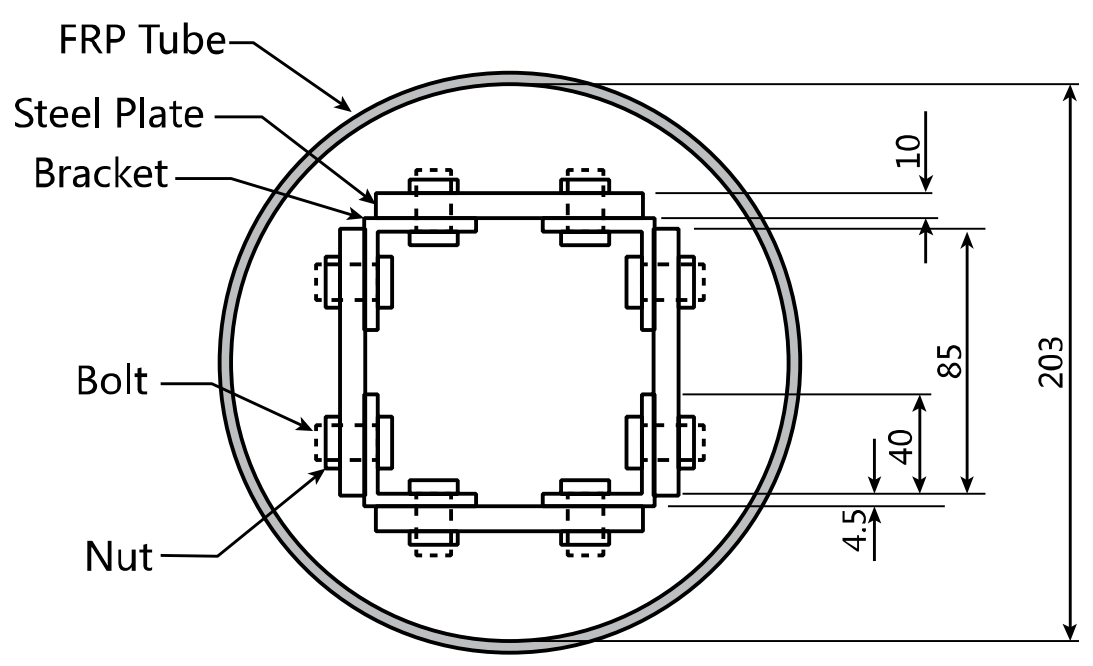

(c) Cross-section of HSSP-CFFTs with plate C

Figure 2. Dimensions of tested specimens 


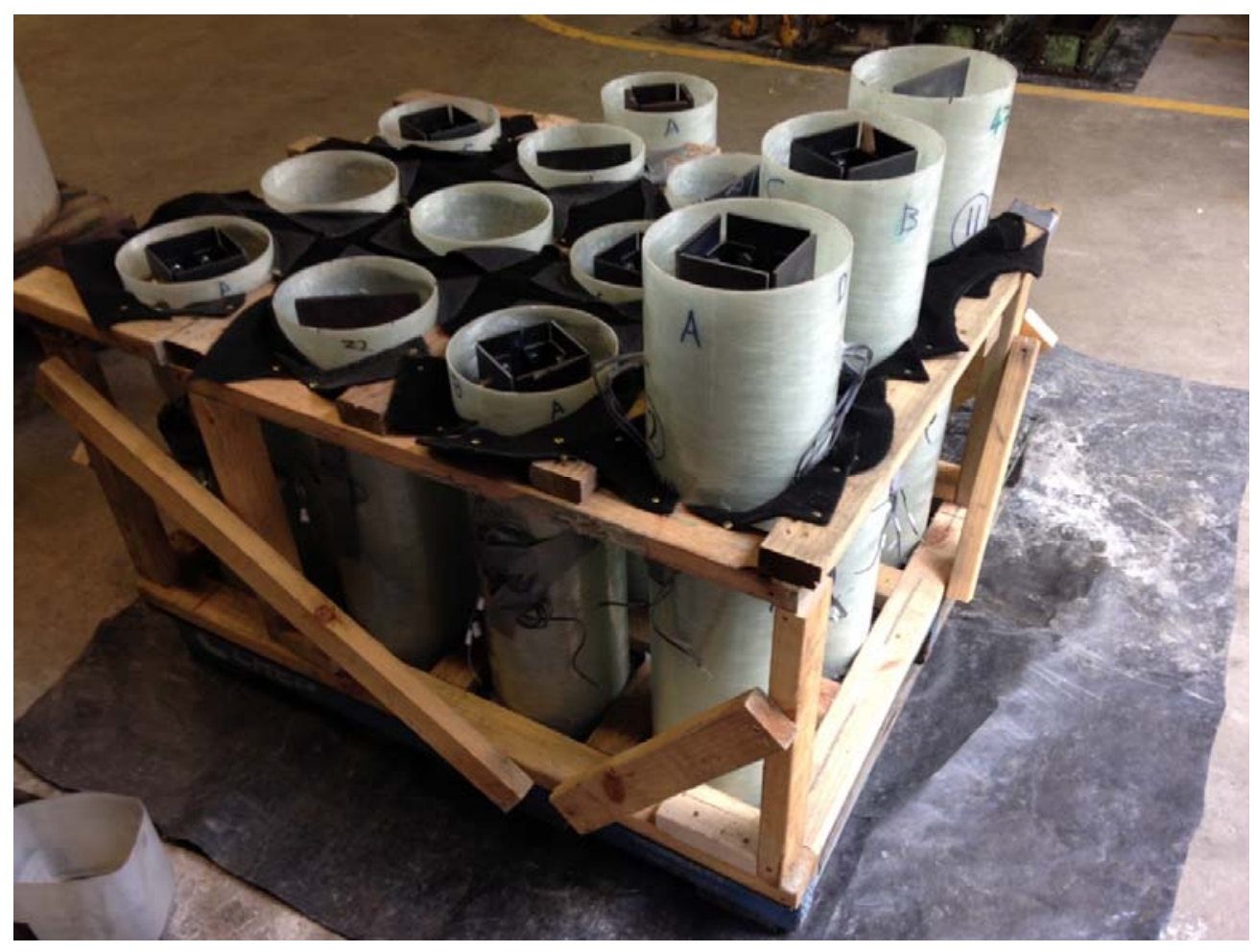

Figure 3. Moulds for casting concrete

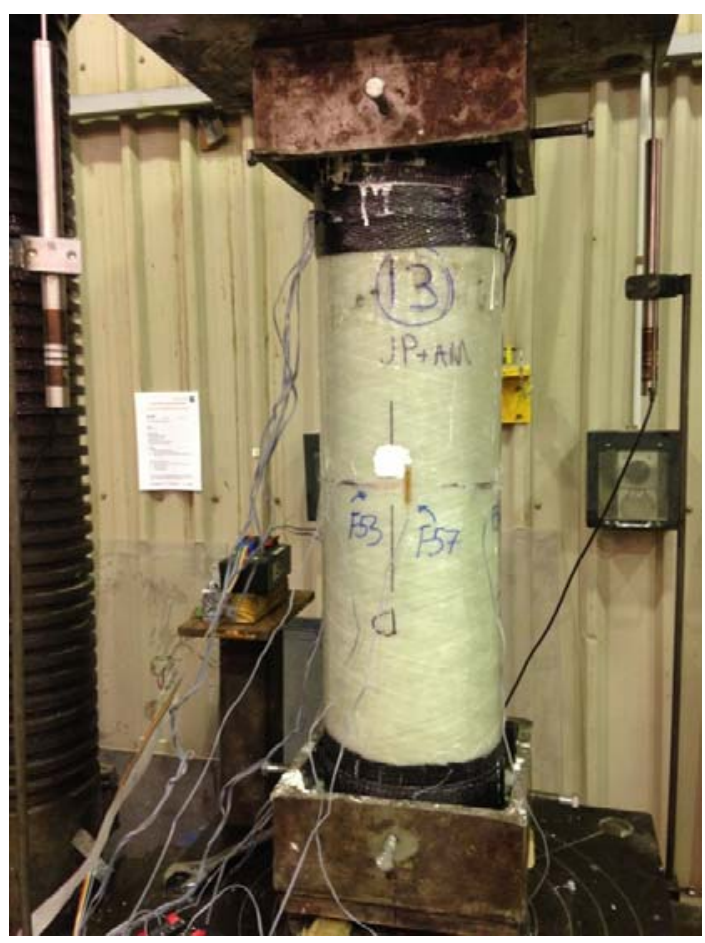

(a) Specimen during test 


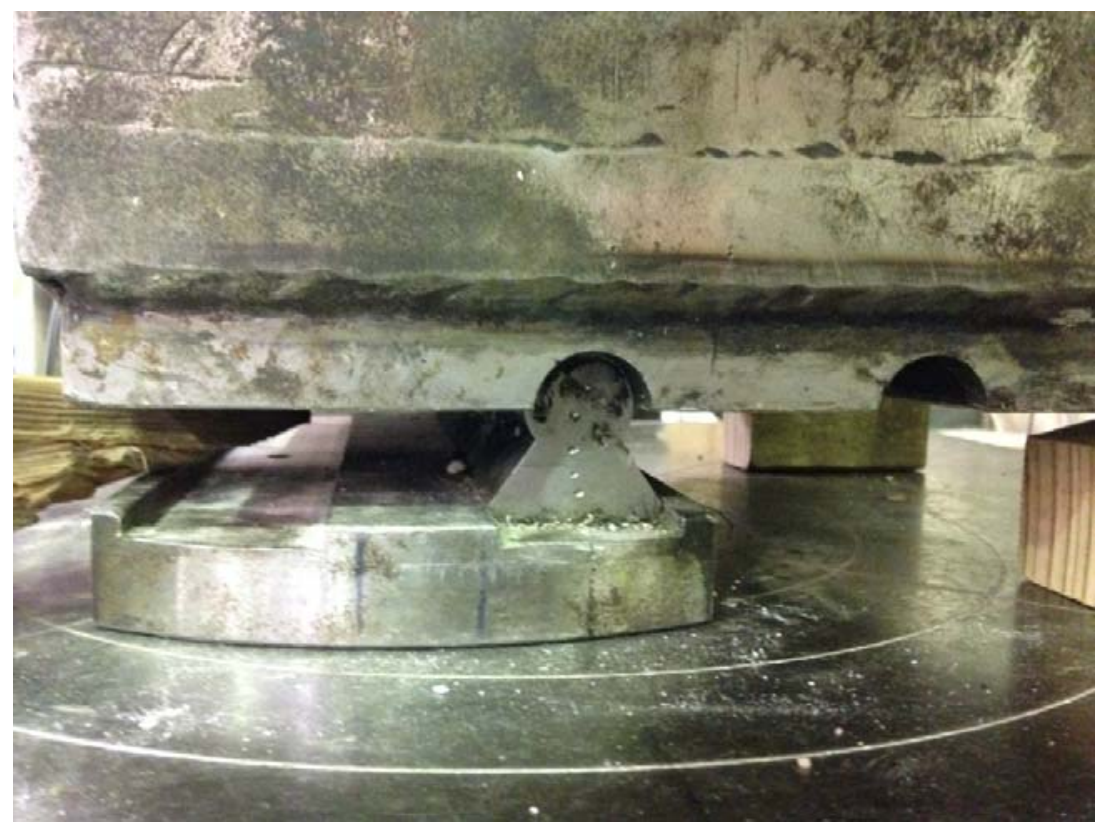

(b) Loading base of eccentric compression tests

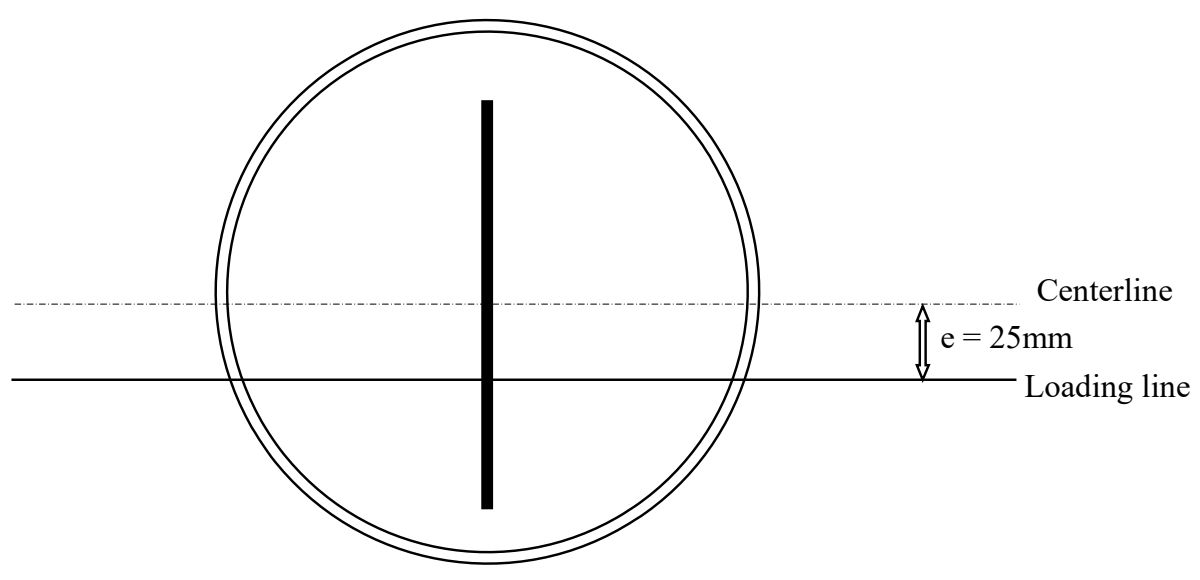

(c) Illustration of eccentric loading for single-plate specimen

Figure 4. Set-up of eccentric compression tests 


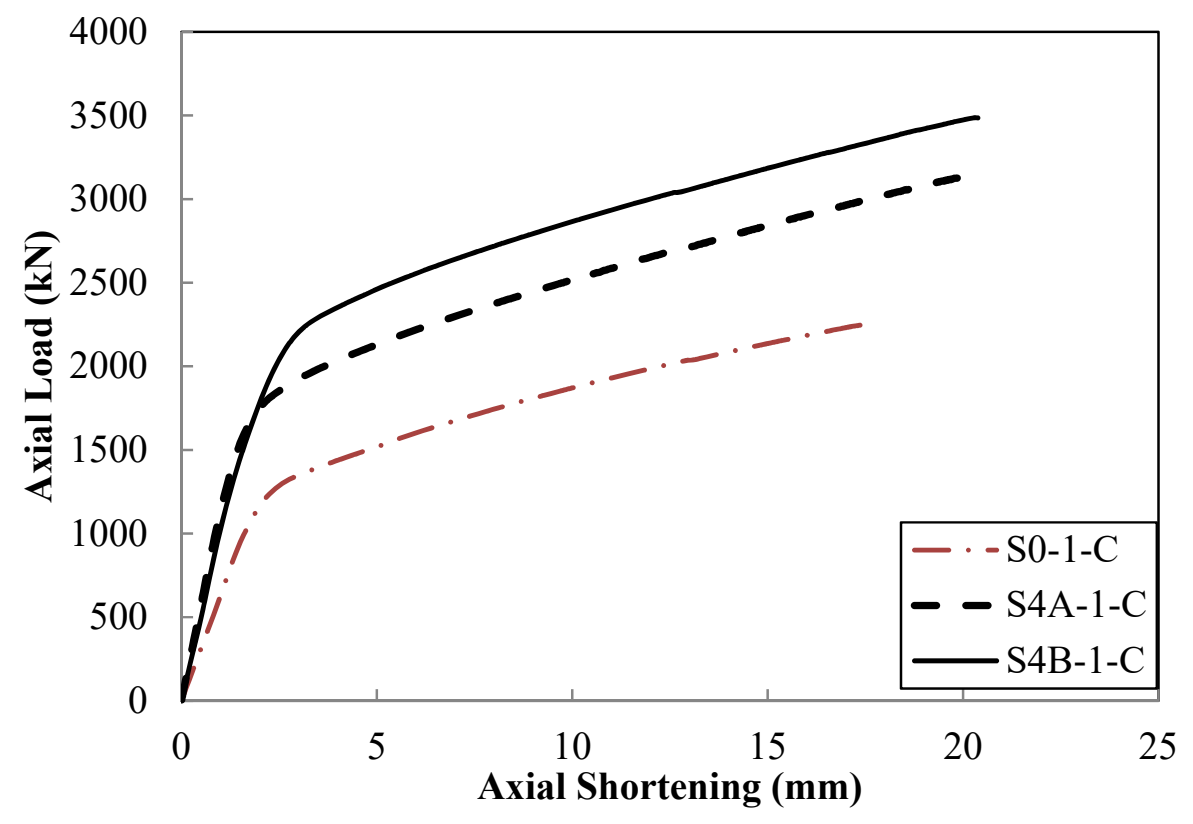

Figure 5. Typical axial load-shortening curves of concentrically-loaded specimens
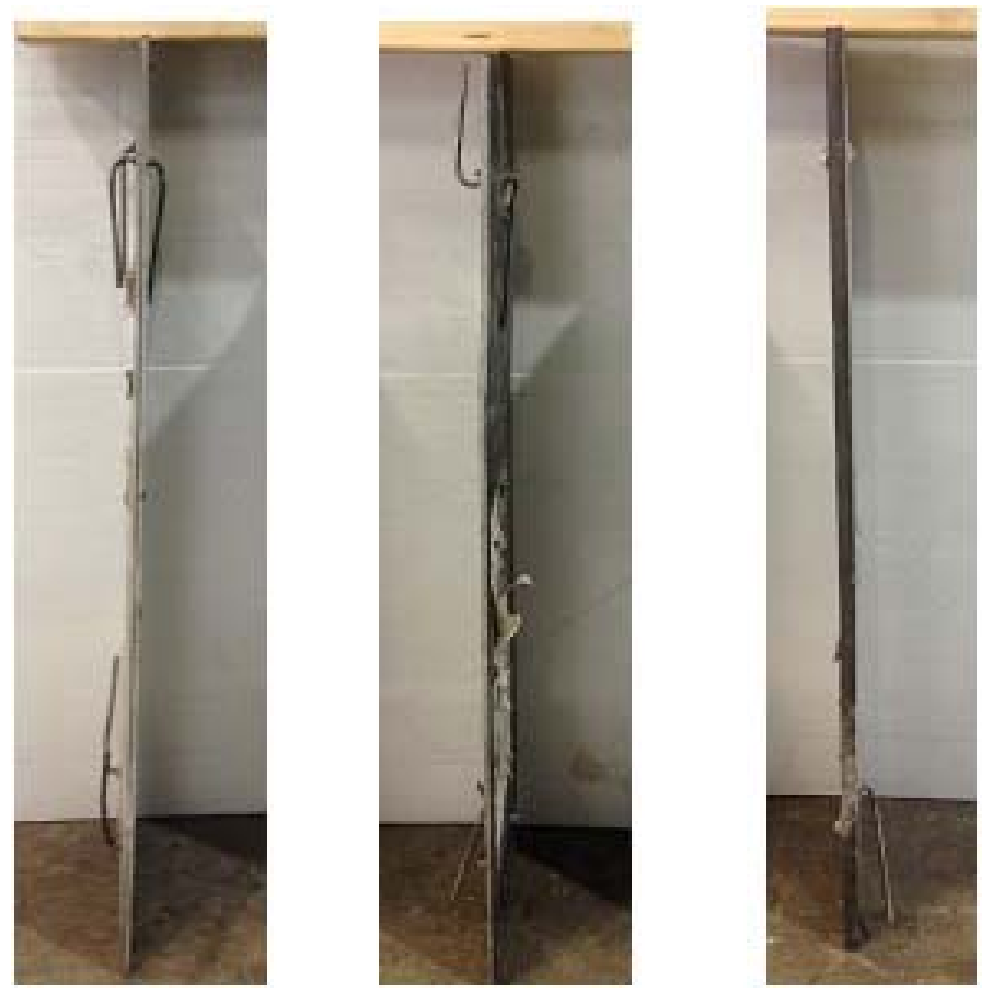

Figure 6. Steel plates from single-plate specimens under concentric compression 


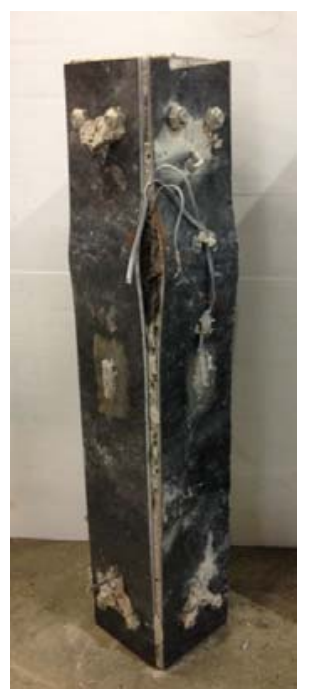

(a) Specimen 4A-3-C

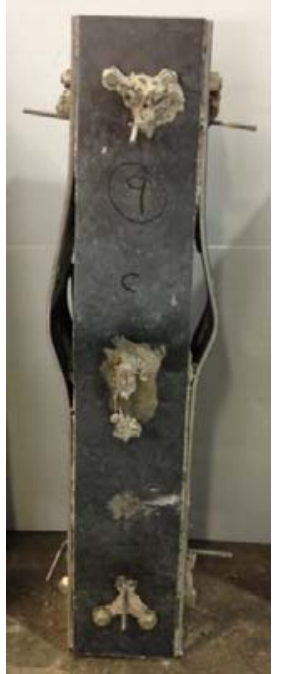

(b) Specimen 4A-1-C

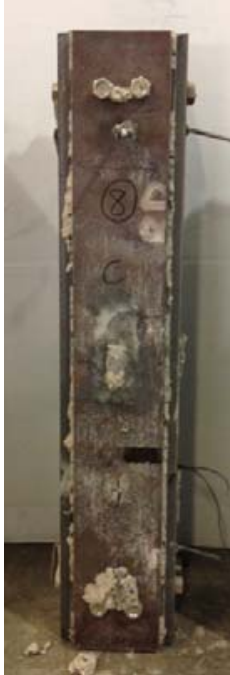

(c) Specimen 4C-3-C

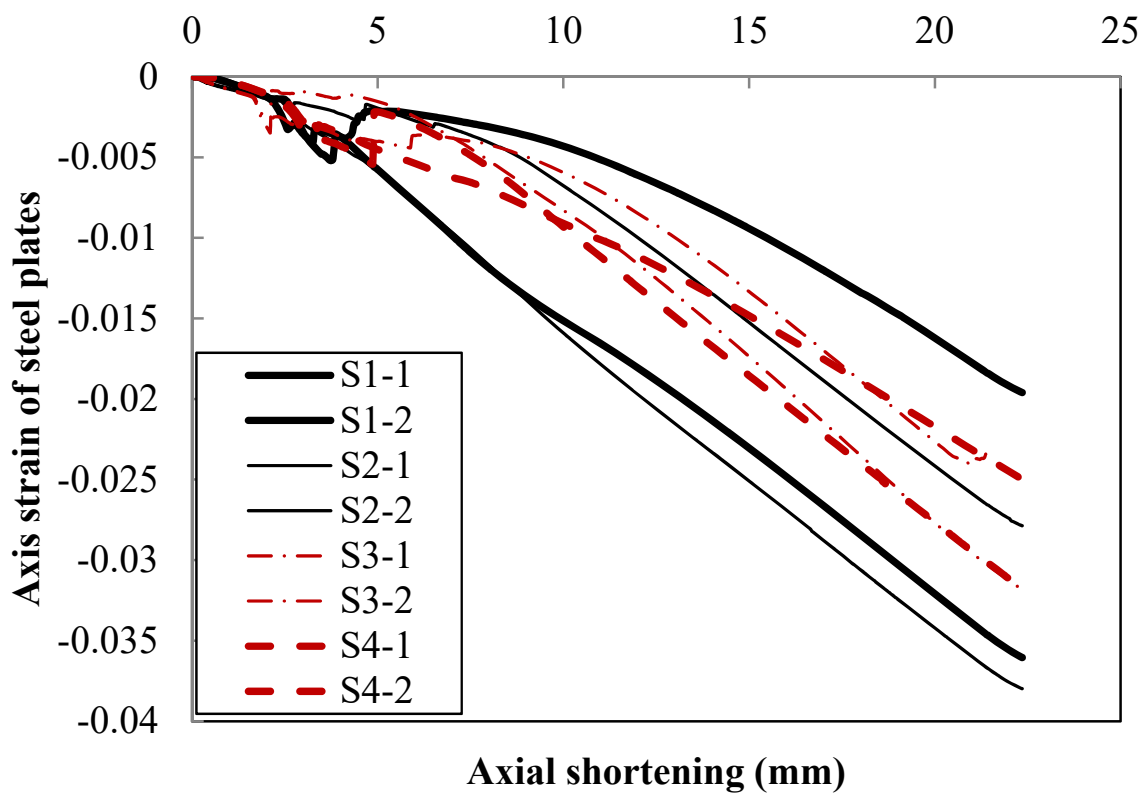

Figure 8. Readings of axial strain gauges on steel plates: specimen S4A-3-C

(a) Square-plate specimens 


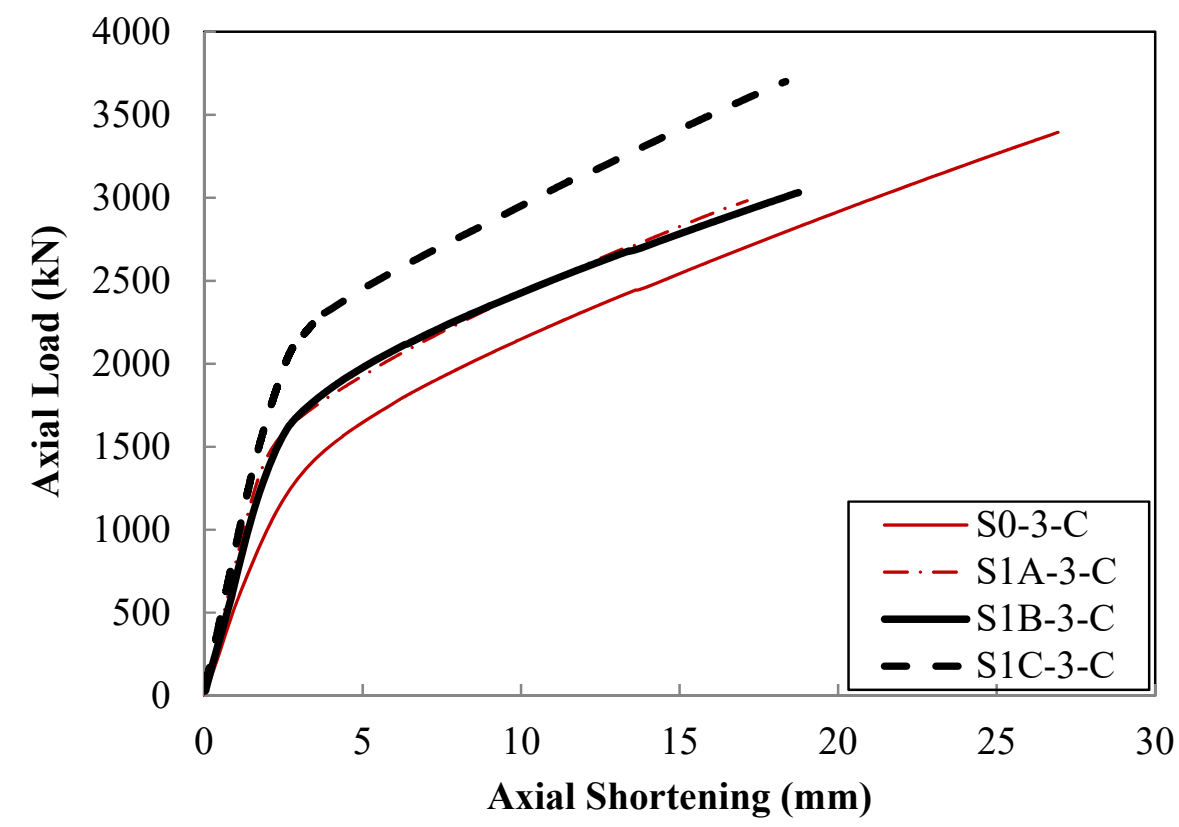

(b) Single-plate specimens

Figure 9. Effect of steel grade

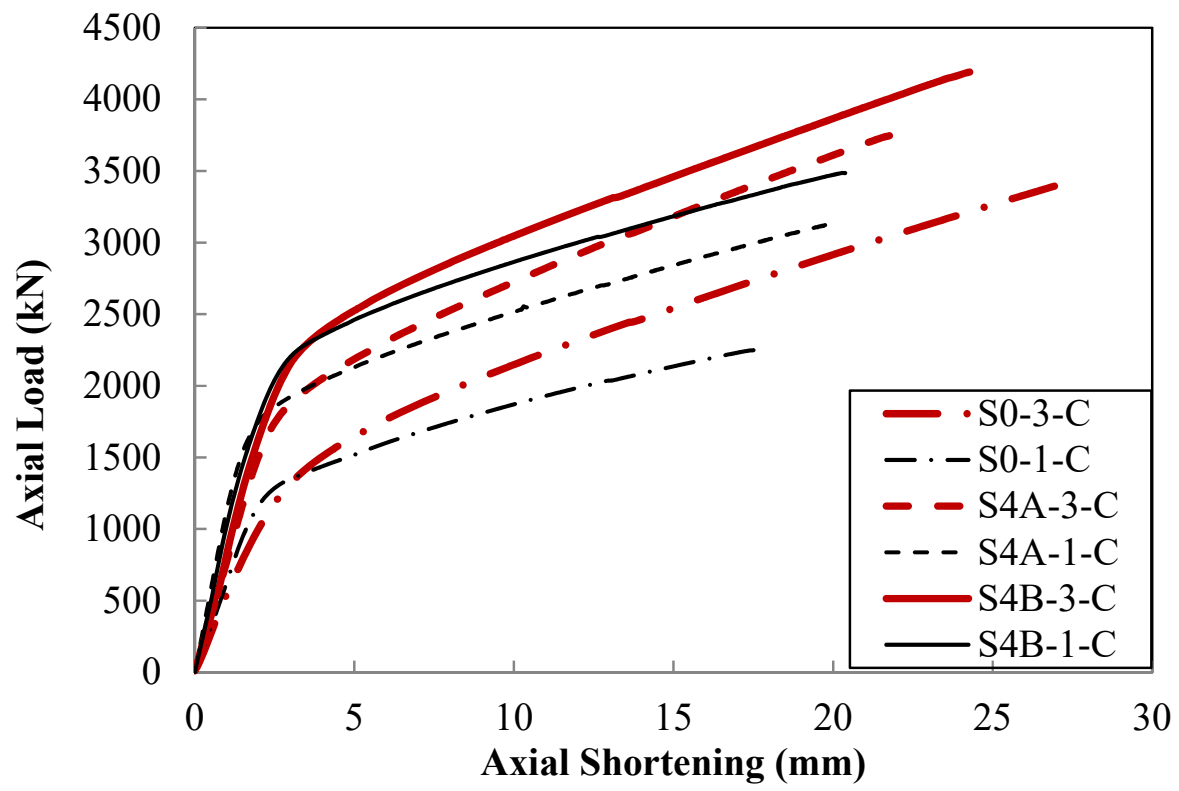

Figure 10. Effect of thickness of FRP tube 


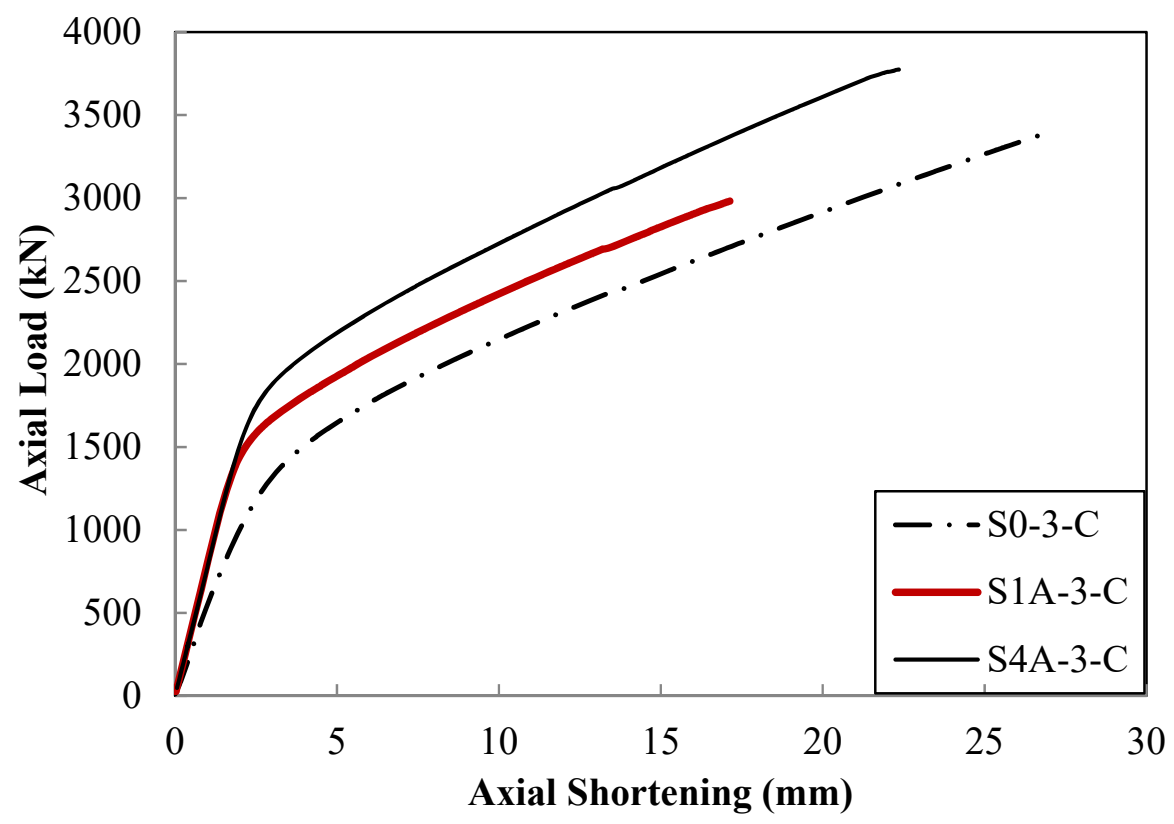

(a)

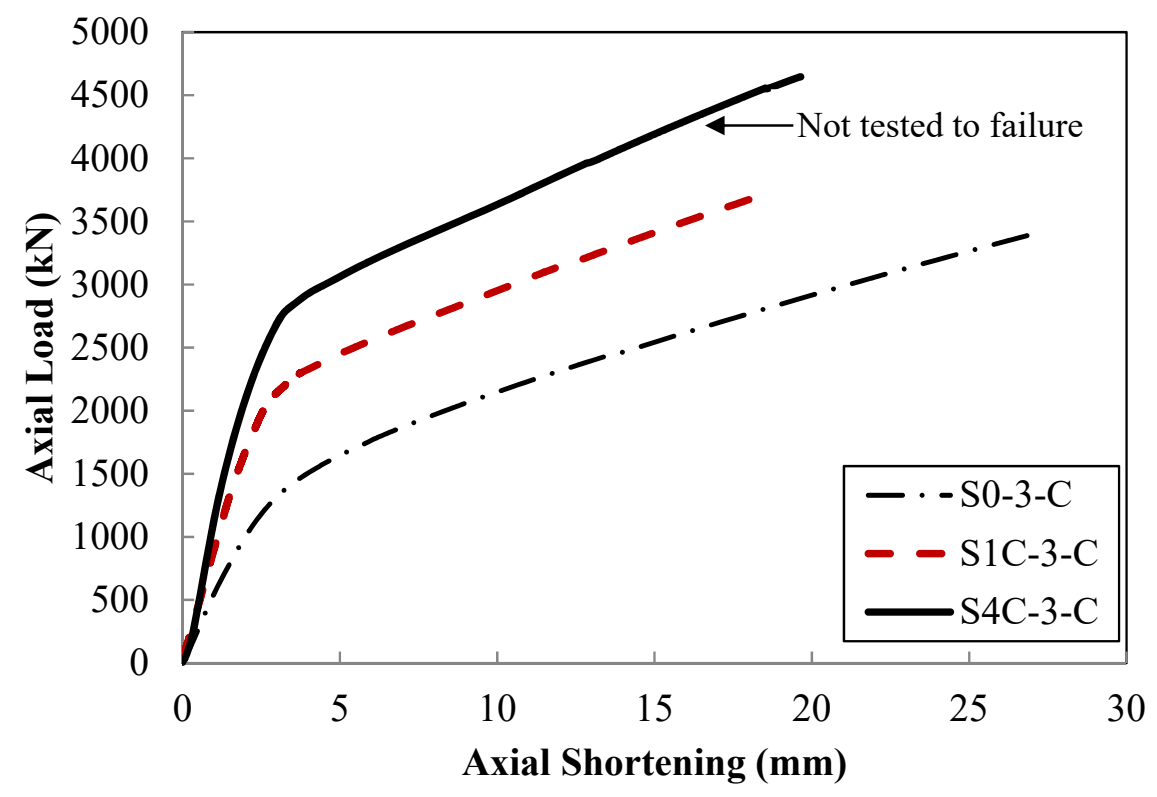

(b) 


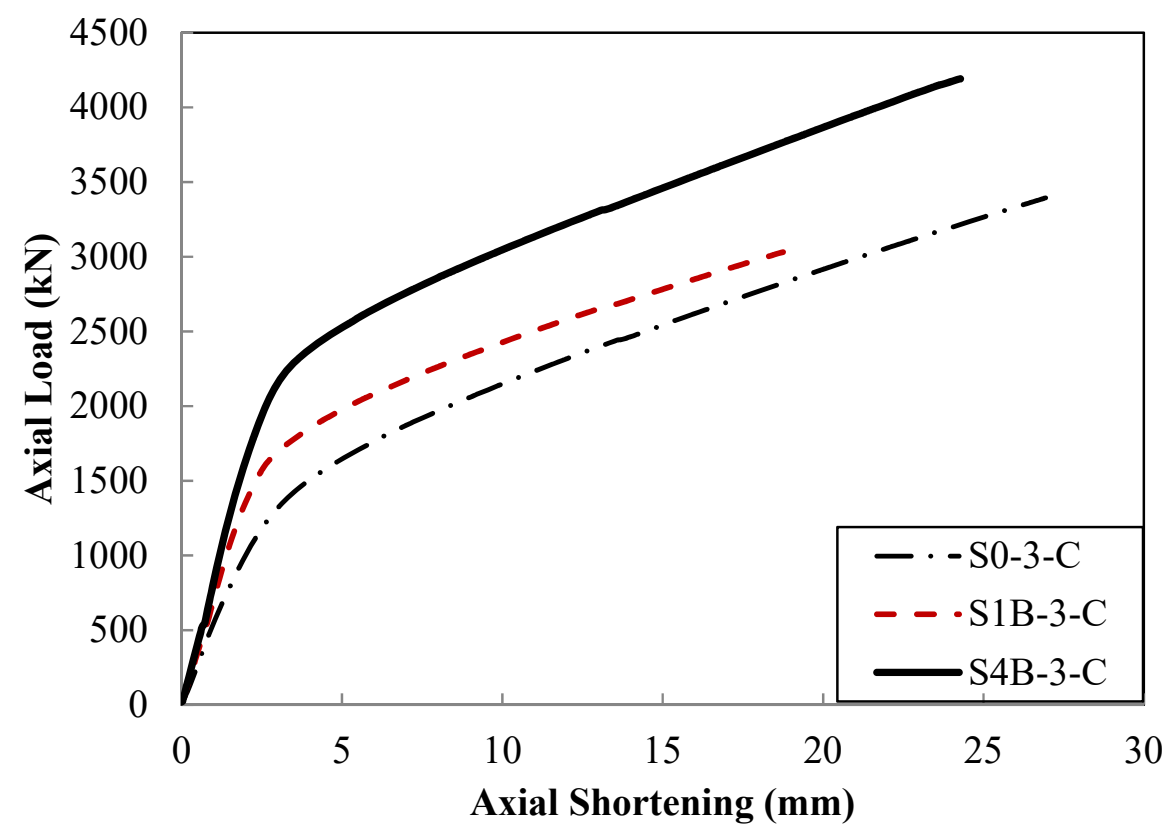

(c)

Figure 11. Effect of configuration of steel plates

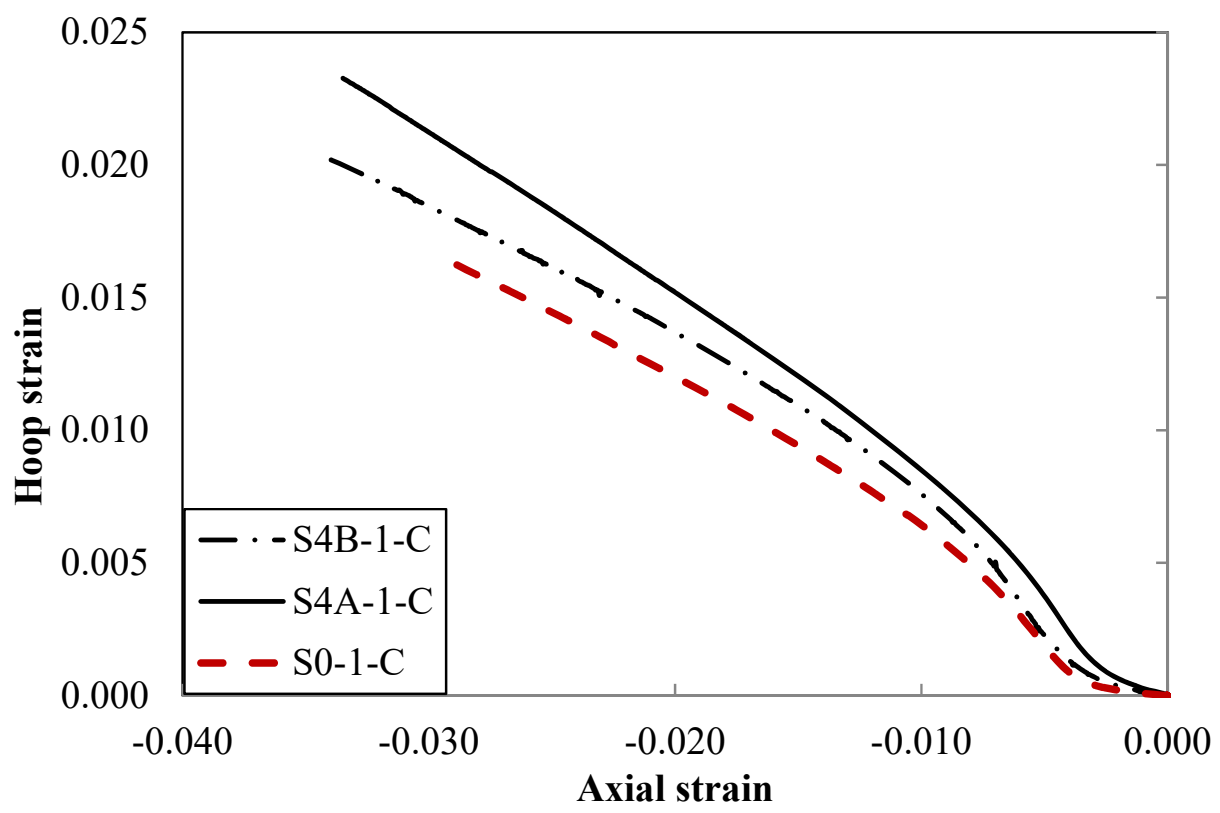

(a) 


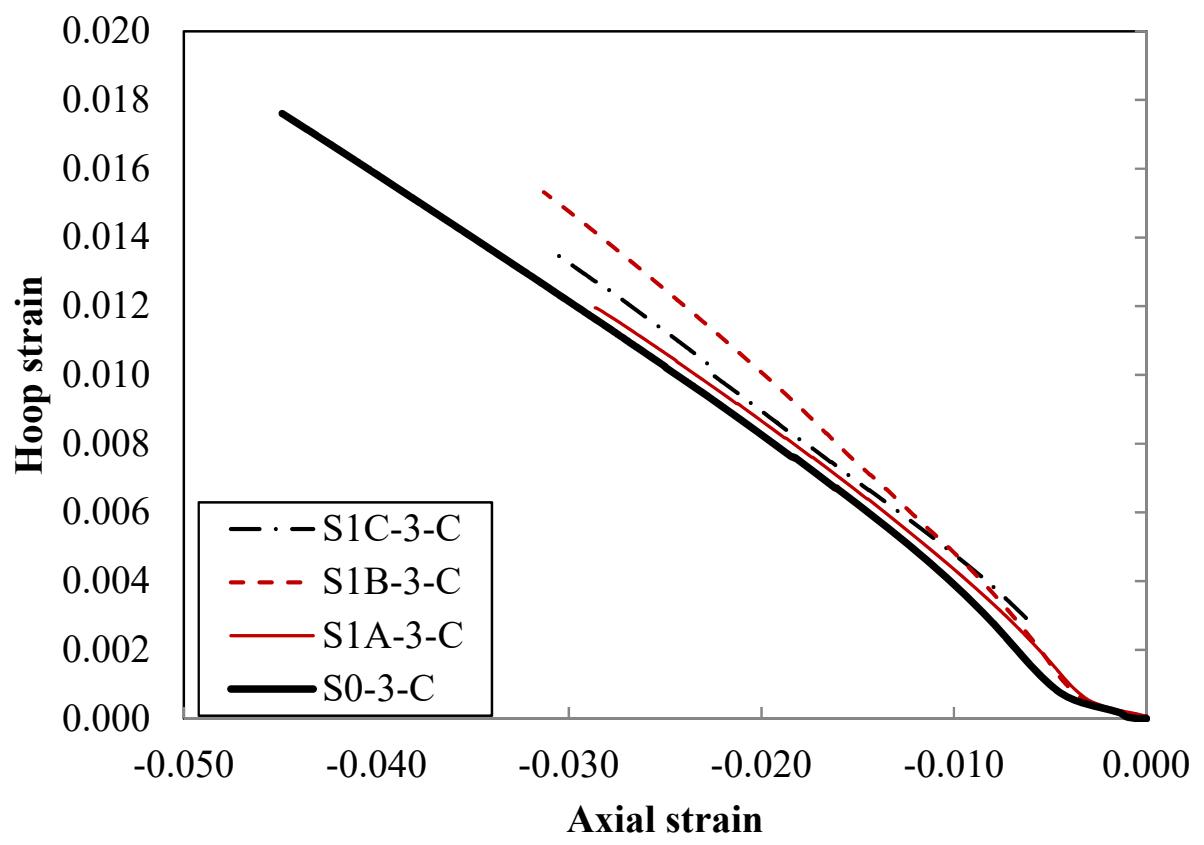

(b)

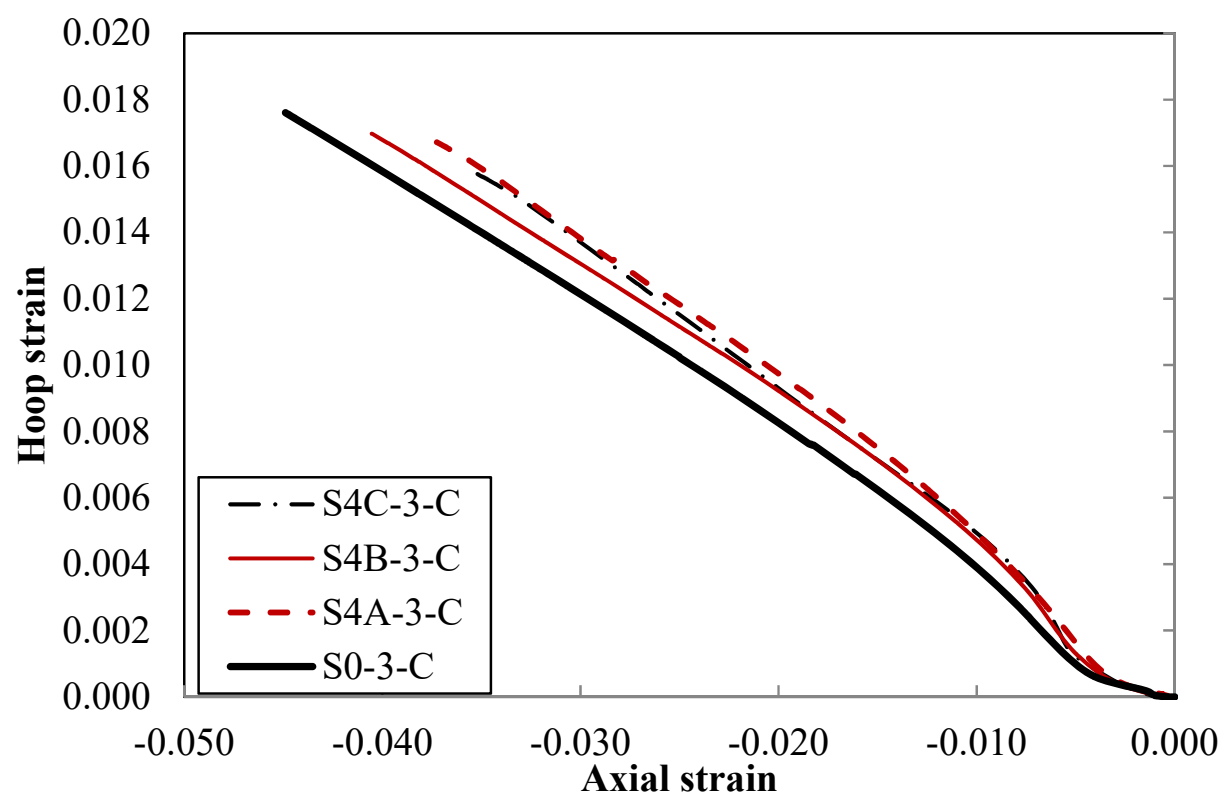

(c)

Figure 12. Axial strain-hoop strain curves 


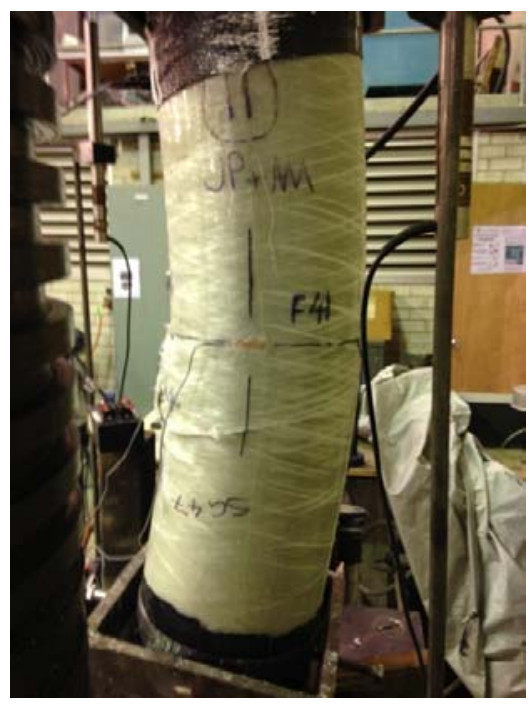

Figure 13. Specimen S1B-3-E after test

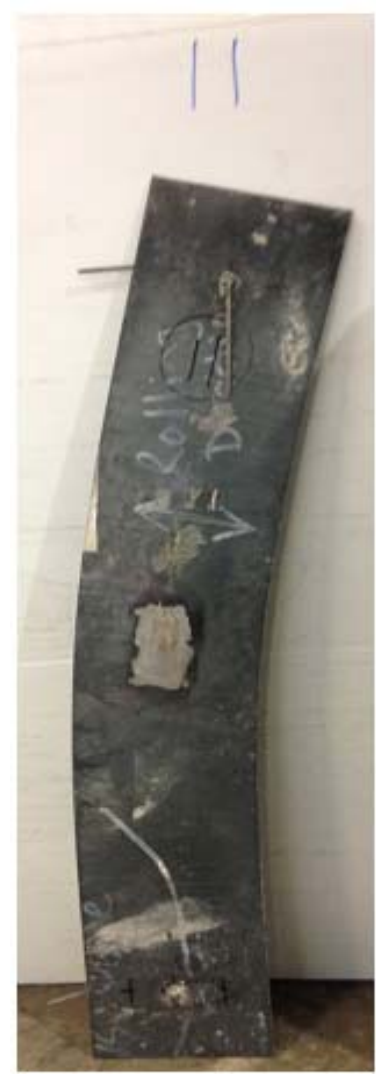

(a) Specimen S1B-3-E

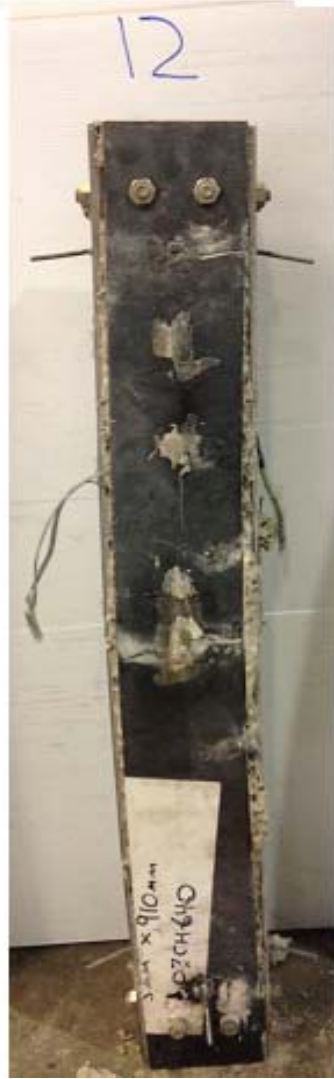

(b) Specimen S4B-3-E

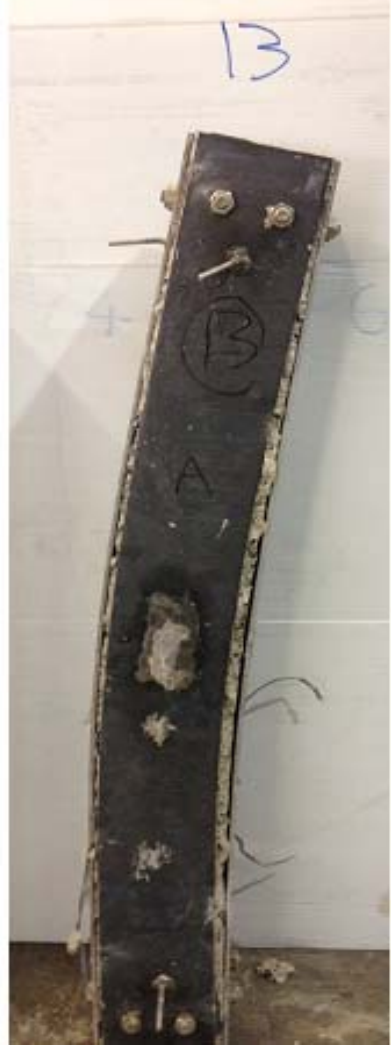

(c) Specimen S4A-3-E

Figure 14. Steel plates from specimens under eccentric compression 


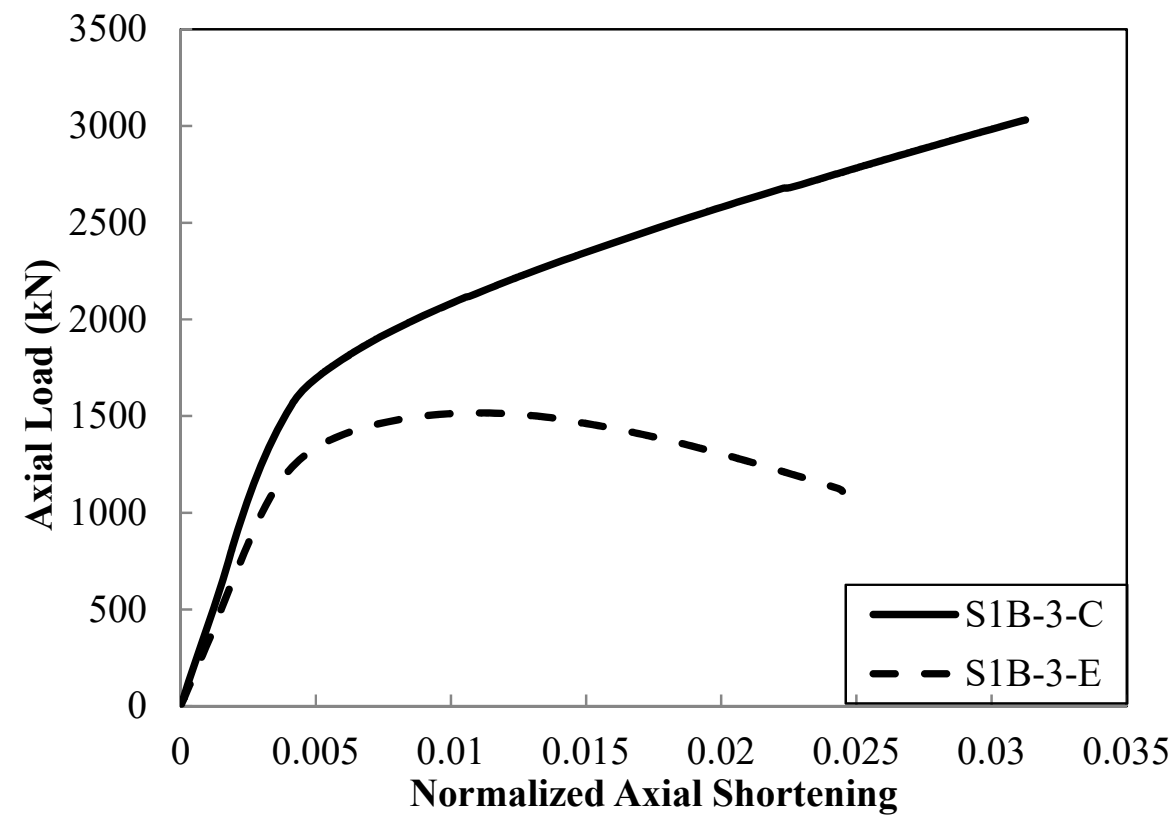

(a)

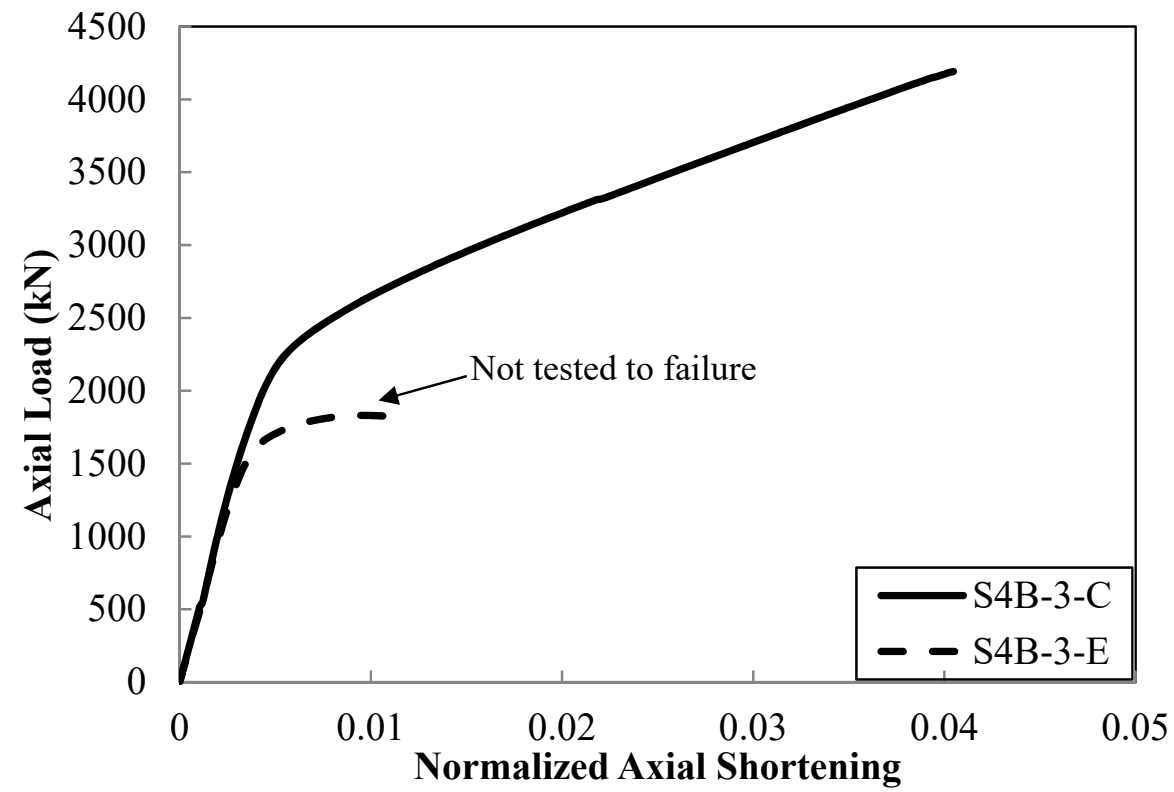

(b) 


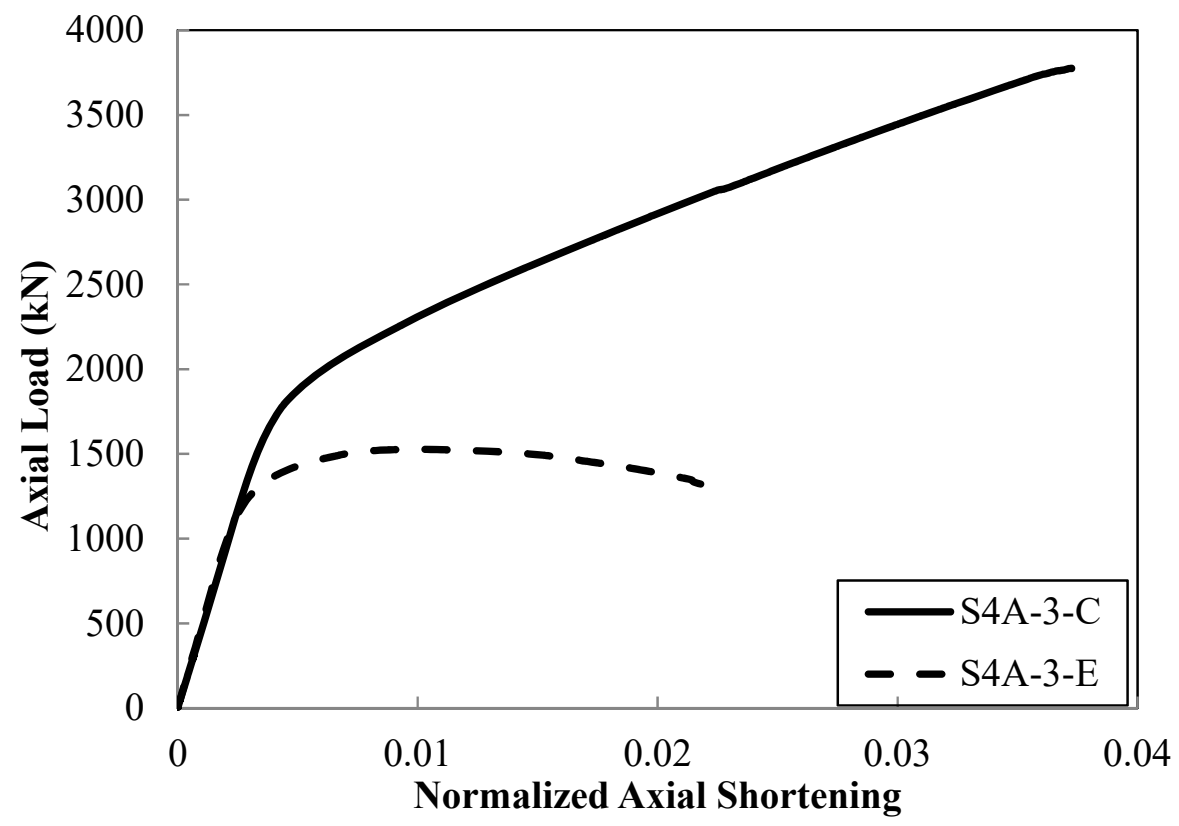

(c)

Figure 15. Axial load-shortening curves of eccentrically-loaded specimens

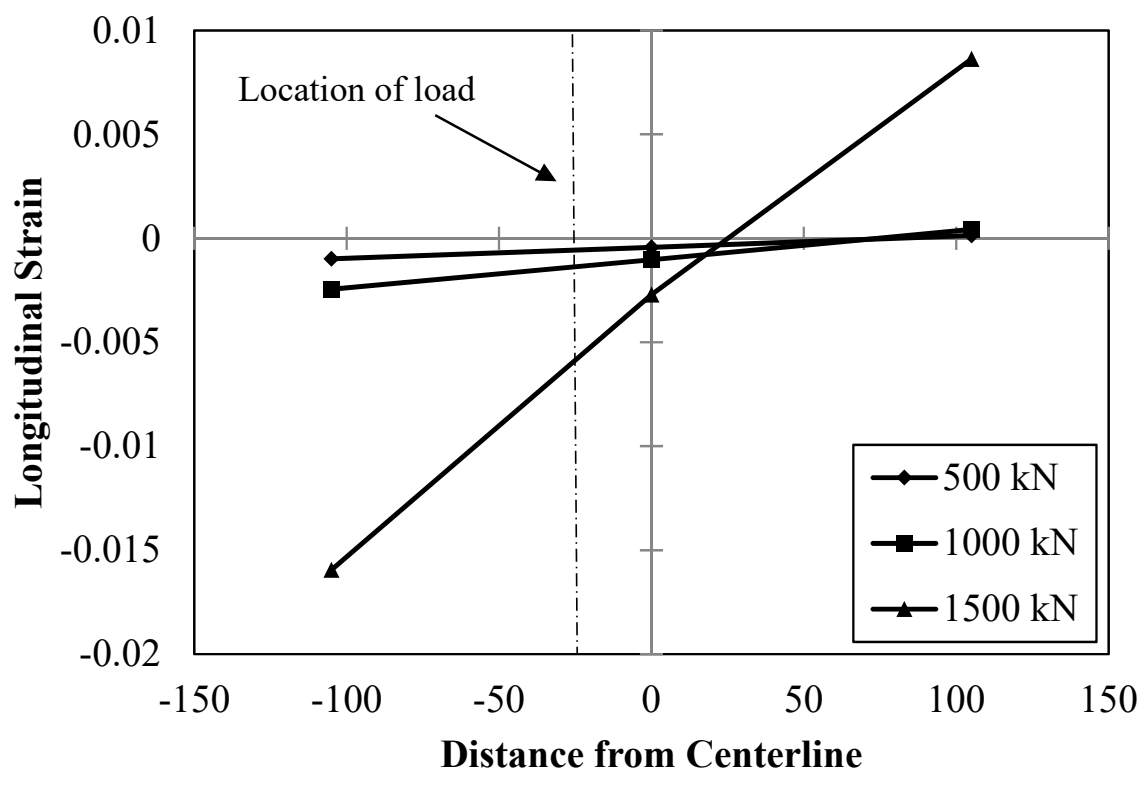

(a) Specimen S1B-3-E 


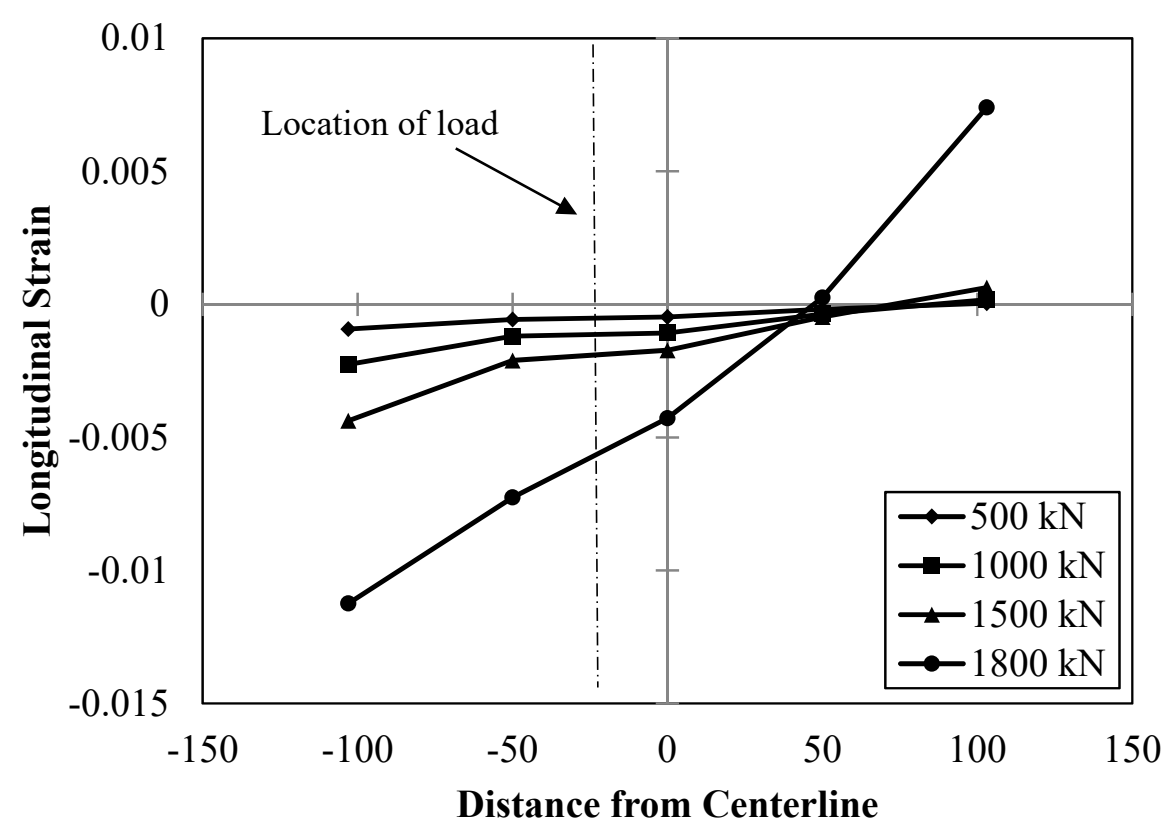

(b) Specimen S4B-3-E

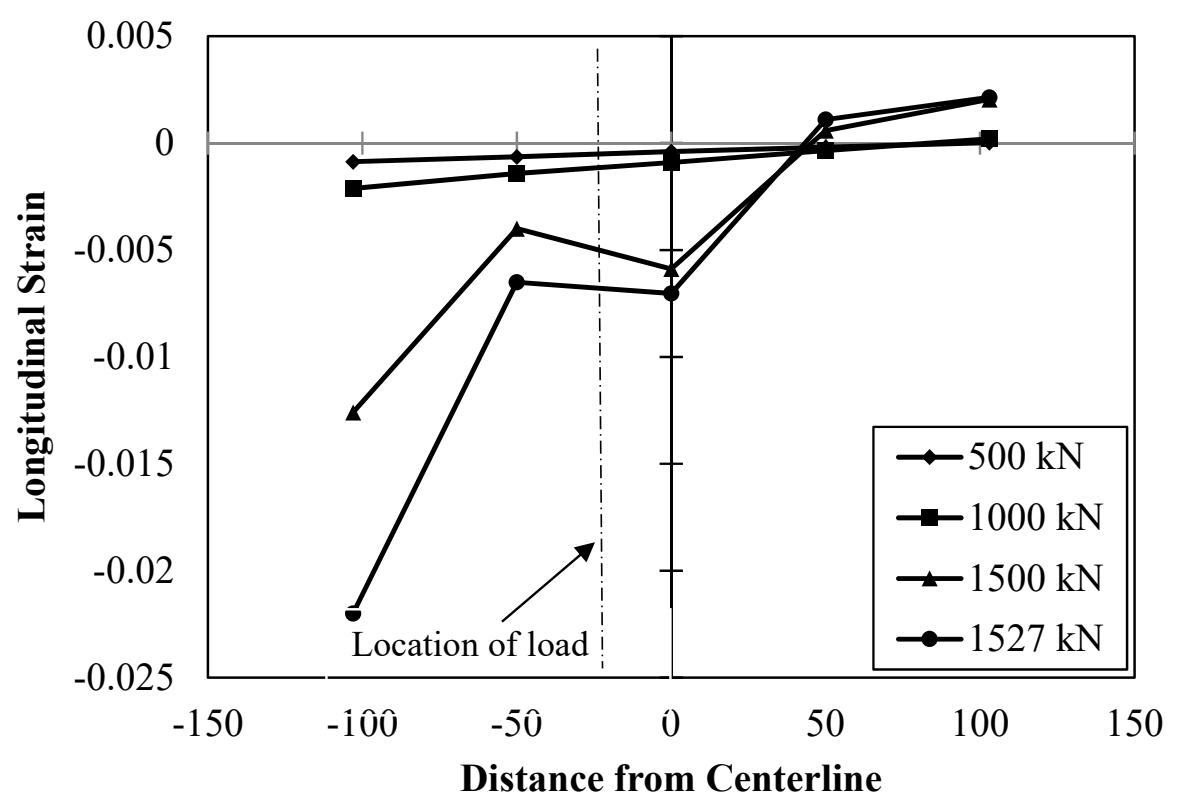

(c) Specimen S4A-3-E

Figure 16. Longitudinal strain distribution 


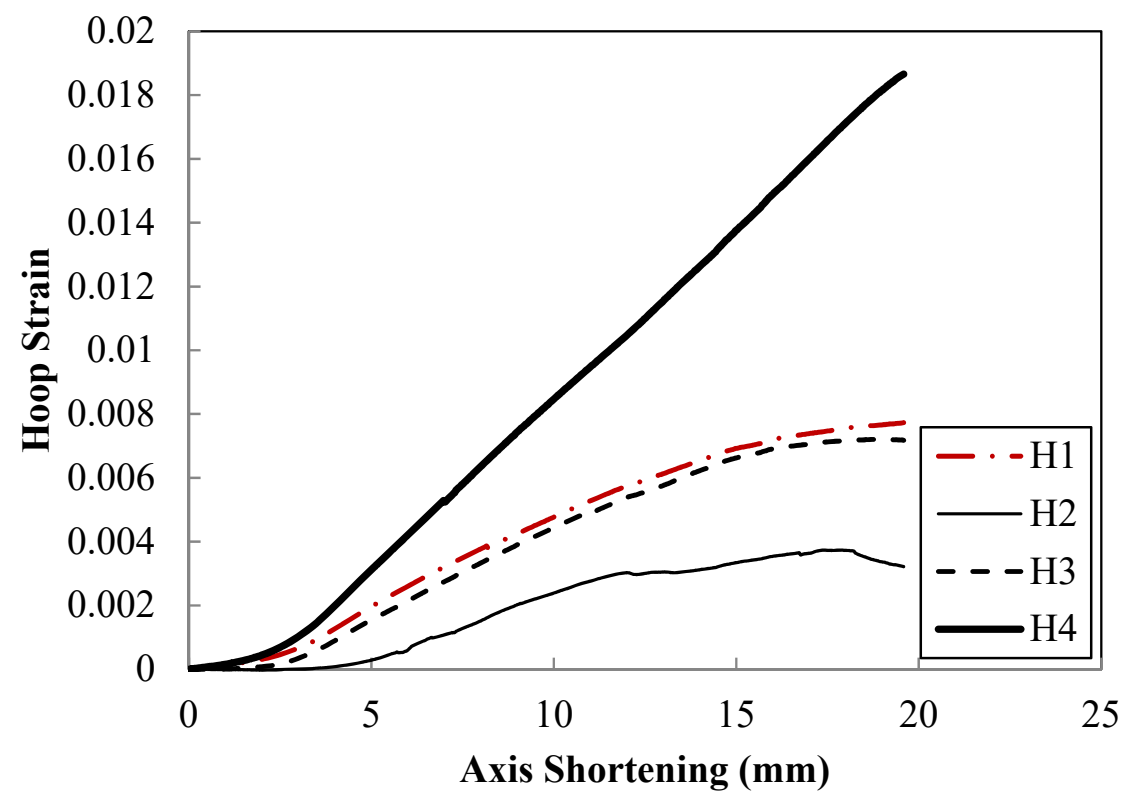

Figure 17. Lateral dilation behaviour of eccentrically-loaded specimens 